\title{
EN BUSCA DE LA BALSA PERDIDA
}

\section{RAIDERS OF THE LOST RAFT}

\author{
BenJAMIN Ballestera
}

Los objetos no poseen solo tres dimensiones, sino tantas como busquemos, todo depende de nuestra capacidad para interrogarlos. Desde 1960, una escultura en piedra de una balsa de cuero de lobo marino tripulada se ha ido posicionando en el discurso de la prehistoria chilena, especialmente del semiárido. Depositada el año 1939 en un museo alemán, por décadas la arqueología la rememora a través de sustitutos escritos, gráficos y escultóricos. La sumatoria de historias, imágenes, narraciones e interpretaciones en torno a esta obra ha creado nuevos objetos virtuales distintos del original. Este ensayo revive sus biografías, coleccionistas, traspasos, viajes, réplicas, rasgos materiales, normas de composición y similitudes con otras piezas. El objeto-balsa será juzgado desde las relaciones e imaginarios que se han tejido en torno a él.

Palabras clave: Escultura en piedra, Balsa, Navegación, La Serena, Diaguita, Inca, Biografía.

Objects do not have three dimensions only, but as many as we look for: it all depends on our ability to interrogate them. Since 1960, a stone sculpture of a manned sea lion skin raft has positioned itself in the discourse of Chilean prehistory, especially of the semiarid. Deposited in 1939 in a German museum, it has been remembered for decades by Chilean archaeology through written, graphic and sculptural substitutes. The summation of stories, images, narrations and interpretations around this work has created new virtual objects that are different from the original. This essay revives their biographies, collectors, transfers, trips, replicas, material features, rules of composition and similarities with other pieces. The object-raft will be judged based on the relationships and imaginary that have been woven around it.

Keywords: Rock sculpture, Raft, Navigation, La Serena, Diaguita, Inca, Biography.
Cuando se estrenó En busca del arca perdida (1981), ${ }^{1}$ de Steven Spielberg, yo aún no había nacido. No recuerdo la primera vez que la vi y probablemente no fue sentado en la butaca de un cine. Es como si conociera la historia de toda la vida. Un arqueólogo, oficiales nazis, la década del 30, los parajes desérticos de El Cairo y un objeto deseado por todos, la misteriosa Arca de la Alianza. Debo admitir que la trama nunca influyó en que hoy sea arqueólogo, sino más bien ello fue consecuencia de mis azarosas decisiones veinteañeras, por lo que hasta hace poco seguía siendo para mí nada más que una buena película.

Sin querer reviví recientemente su historia como si fuera un remake. En febrero de 2019 viajé a Alemania a estudiar un objeto arqueológico excepcional depositado en el Museum am Rothenbaum - Kulturen und Künste der Welt ${ }^{2}$ (MARKK) de Hamburgo. Se trata de una escultura en piedra que representa una balsa de cuero de lobo marino con dos tripulantes en su interior, cuyo origen sería algún cementerio en los alrededores de La Serena, en el semiárido de Chile, comprada por el museo en la década de 1930 al doctor Ricardo Schwenn, un conocido coleccionista de la ciudad. Luego de analizar y fotografiar la pieza en detalle, tuve acceso a un archivador lleno de documentos mecanografiados y escritos a mano alzada datados entre 1936 y 1952, todos en alemán. De ellos se desprende que el doctor Schwenn se contactó con el

A Benjamín Ballester, UMR7041-ArScAn, Équipe Ethnologie Préhistorique, Université Paris 1 Panthéon-Sorbonne, Francia. orcid: 0000-0002-7677-717X. E-mail: benjaminballesterr@gmail.com 
museo para vender la pieza junto a un paquete de otros 882 objetos. Todas las cartas, telegramas e informes bilaterales previos a 1946 están firmados al final del texto con un notorio "Heil Hitler?", además de estar adornados de estampillas y timbres nazis con el característico ícono del águila germana sobre la esvástica. La aparición de estos símbolos no debe ser tema para quienes trabajan día a día en el museo, pero para una persona ajena a su historia, el hallazgo fue en un principio chocante, luego del todo inusual, y al final, casi tan cautivante como la balsa por la cual había viajado hasta Alemania.

Casualidad o no, En busca del arca perdida está ambientada en 1936, mismo año en que el Hamburgisches Museum für Völkerkunde ${ }^{3}$ comienza el proceso de compra de la colección arqueológica al doctor Schwenn en nombre del Führer. Al salir del museo, de inmediato recordé la escena de Indiana Jones persiguiendo a caballo los Mercedes Benz alemanes por un sinuoso camino de tierra. Mi primer encuentro con la materialidad nazi fue sin lugar a dudas menos avezada y audaz comparada con la que protagonizó Harrison Ford casi 40 años atrás. Más allá de lo diferente de nuestras historias -una ficción, la otra realidad-, me parece notable como un simple objeto de piedra puede terminar tejiendo una trama que liga experiencias distantes y recuerdos olvidados, más aún vincular a sujetos lejanos en el tiempo y en el espacio al hacerlos copartícipes de un mismo guion que luego deviene sumamente significativo en la vida de estas personas.

No cabe duda de que en esta trama colectiva las trayectorias que experimentan los objetos, tal como los humanos y otros seres, pueden ser calificadas como biografías (Alberti 2005, Gosden \& Marshall 1999, Hoskins 2006, Kopytoff 1991). La balsa de piedra depositada hoy en Hamburgo es prueba de ello. Este ensayo, sin embargo, pretende ir un poco más allá, para discutir sobre quiénes escriben y cómo se han redactado estas biografías, pues tras ellas existe un proceso de inscripción que es tanto o más relevante en su configuración que las vivencias mismas de los objetos.

La singular escultura de piedra ha sido constantemente evocada en la literatura arqueológica desde la década de 1950. Biografía tras biografía los relatos sobre ella han ido transformándose. Para aplacar la distancia, la obra primigenia desplazada de su origen fue una y otra vez remplazada por ilustraciones, fotografías y réplicas que fueron acarreando con el paso del tiempo una cadena de reconversiones producto de la sumato- ria de imperfecciones. Ambos fenómenos, escritos y visuales, crearon un nuevo objeto, o más bien varios nuevos objetos, ahora virtuales, distintos del que yace todavía guardado tras una vitrina en el Museum am Rothenbaum. Este ensayo es un intento por rastrear la larga historia de la balsa de piedra, de hacer visibles sus transmutaciones virtuales en los relatos e imágenes, juzgar sus reproducciones y desenredar la compleja red de vínculos y relaciones entre personas y cosas que se ha ido tejiendo por generaciones en torno a ella. Un ejercicio que busca al mismo tiempo deconstruir y crear la balsa, para dar finalmente aún más densidad a la roca, volumen al cuenco y profundidad al objeto. La tentativa es superar sus tres dimensiones.

\section{RELATOS ESCRITOS}

La biografía inaugural sobre la escultura fue publicada en 1953 por el entonces responsable de la colección de América del Hamburgisches Museum für Völkerkunde, Hans Becher. De formación en antropología, prehistoria y estudios americanos, quedó sorprendido por el singular modelo de piedra. Entregó un informe detallado y minucioso de sus medidas, peso, forma, componentes y materia prima. Realizó una comparación entre la escultura y las balsas de cuero de lobo marino descritas por Rudolph Philippi, William Bolleart, Alcides D’Orbigny, Edmond Paris, Gualterio Looser y Samuel Lothrop, contextualizando con la información de Junius Bird. Hans Becher aseguró que la pieza fue descubierta durante un arado en el lado norte del río Coquimbo en "Alto Vassol", a 18 kilómetros de La Serena, y que fue obra del pueblo chango con influencias de los incas. Dos láminas complementan la publicación, la famosa ilustración de Rudolph Philippi, de Caleta del Cobre, y la primera fotografía de la escultura de piedra (fig. 1a).

En la escena chilena, la obra aparece en 1960 en el artículo Las balsas de cueros de lobo inflados de la costa de Chile, de Gualterio Looser. Al parecer, el hallazgo de la pieza por parte del antiguo jefe de la sección de Arqueología, Antropología y Etnología del Museo Nacional de Historia Natural había sido reciente, pues no lo menciona en su texto previo de 1938 dedicado exactamente al mismo tema. La novedad surge justamente por la lectura del artículo de Hans Becher (1953). Traduce y replica la mayor parte de lo escrito por el autor alemán, inclusive pasajes de la carta de Max Uhle 

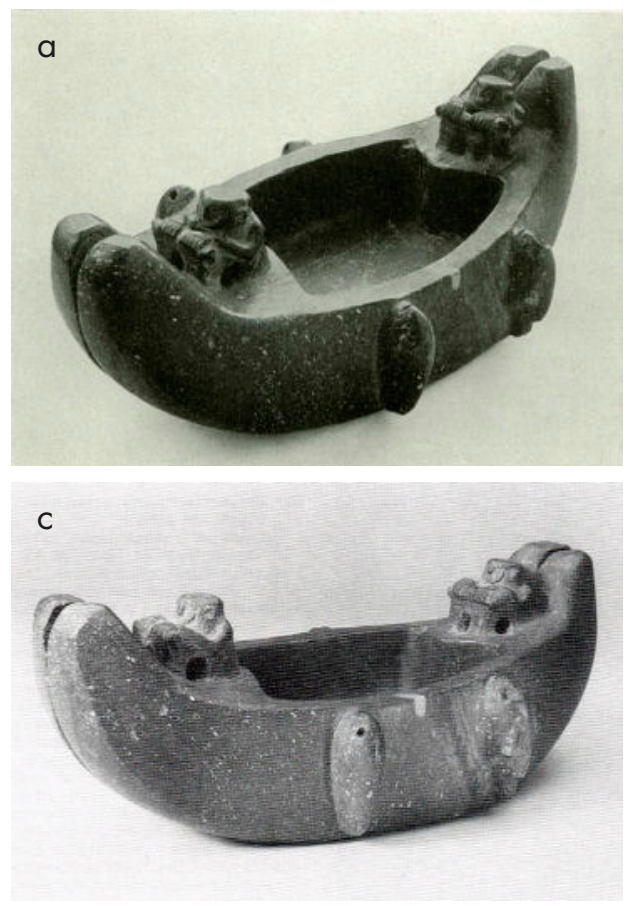

e
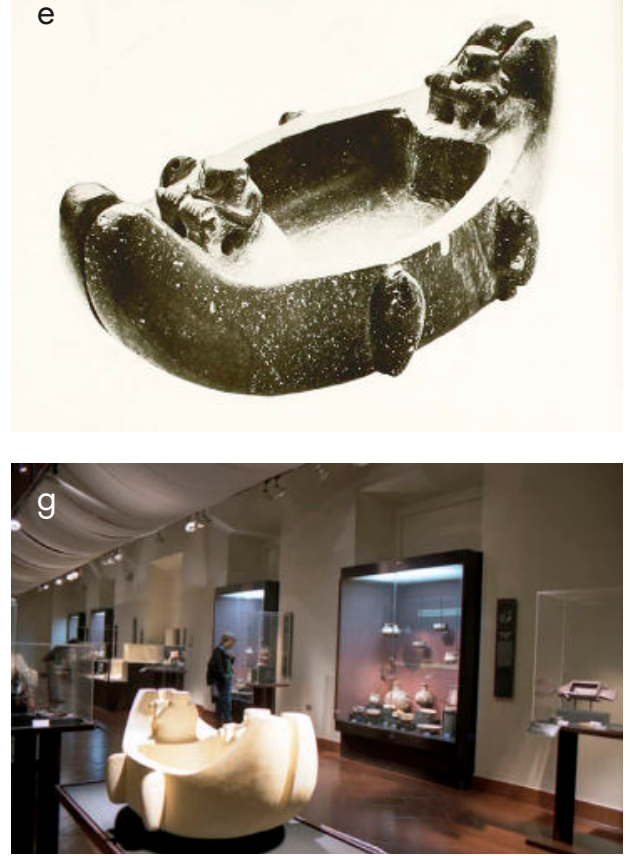

b
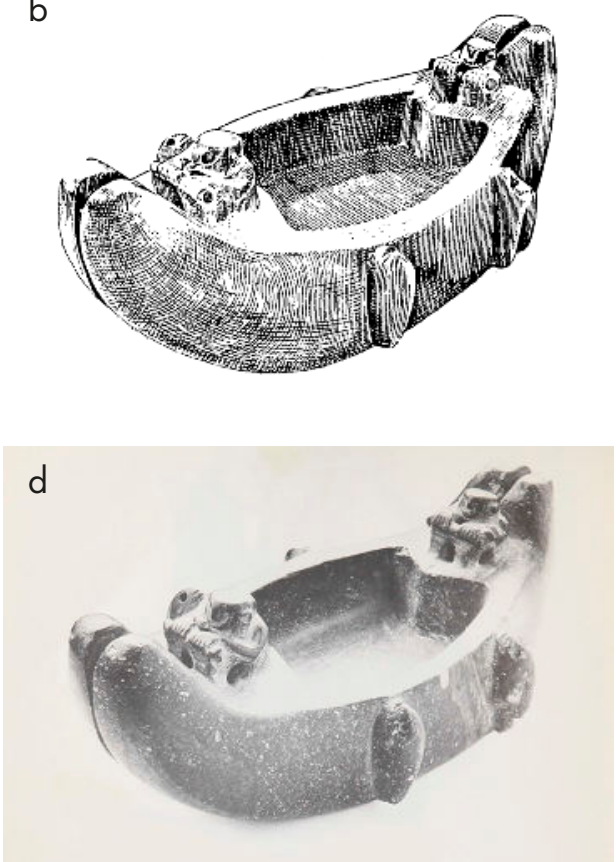

f
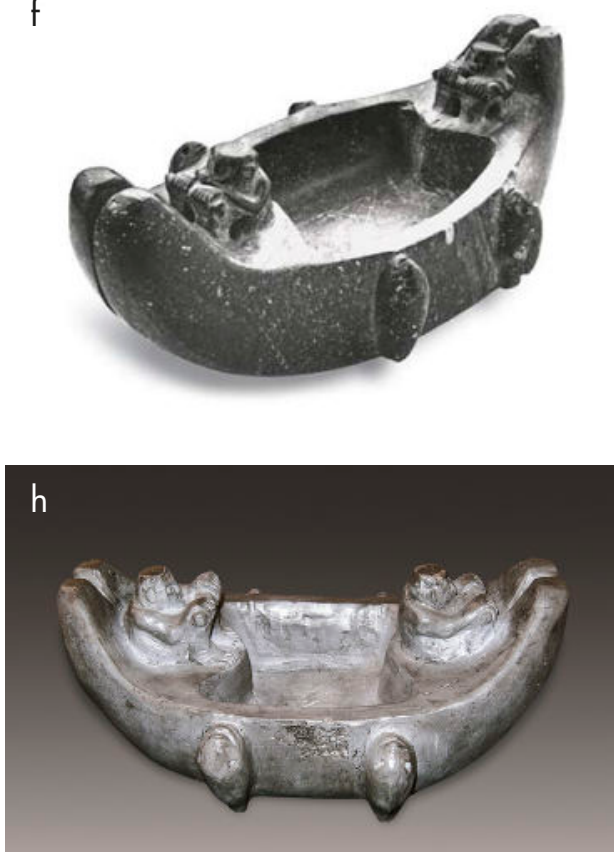

Figura 1. Réplicas gráficas de la balsa de piedra: a) Hans Becher (1953: Abb.1); b) Gualterio Looser (1960: fig. 5); c) Wolfgang Haberland (1984: 335); d) Gonzalo Ampuero (1986: 34); e) Lautaro Núñez (1986: fig. 8); f) José Berenguer (2008: 39); g) José Berenguer y Andrea Torres (2011: 108); h) Gloria Cabello (2016: fig. 13a). Figure 1. Graphic replicas of the stone raft: a) Hans Becher (1953: Abb.1); b) Gualterio Looser (1960: fig. 5); c) Wolfgang Haberland (1984: 335); d) Gonzalo Ampuero (1986: 34); e) Lautaro Núñez (1986: fig. 8); f) José Berenguer (2008: 39); g) José Berenguer and Andrea Torres (2011: 108); h) Gloria Cabello (2016: fig. 13a) 
acerca de la balsa, redactada en 1939 luego de su visita al Hamburgisches Museum für Völkerkunde. En ella asegura que se trata de una obra precolombina, típica de la cultura chilena y hecha sobre piedra roja. En una nota al pie, Gualterio Looser (1960: 253) especula que la balsa debió ser parte de la colección del Dr. Schwenn de La Serena, ya que Francisco Kahler le había obsequiado una pequeña fotografía de la pieza tomada por su hermano Walter Kahler mientras se encontraba aún en manos del coleccionista. Gualterio Looser acompaña el texto con descripciones, algunas interpretaciones y una ilustración de la escultura basada en la fotografía publicada por Hans Becher (fig. 1b).

Pocos años después, Hans Niemeyer menciona brevemente la escultura en su publicación de 1965-1966 dedicada al último constructor de balsas de cuero de lobo marino en Chañaral de Aceituno. Según el autor, la balsa fue modelada sobre una roca de andesita y provendría de un sector llamado el "Islón", seis kilómetros hacia el interior de La Serena por el valle del Elqui. Una reseña aún más acotada fue entregada por Bente Bittmann en su poco considerado artículo Fishermen, mummies and balsa rafts on the coast of northern Chile, del año 1978. En ambos casos prácticamente toda la información proviene del artículo de Gualterio Looser (1960).

La guía de colecciones del Hamburgisches Museum für Völkerkunde del año 1984 dedica media plana a la balsa de piedra con una pequeña leyenda junto a una fotografía en blanco y negro que la muestra de perfil y levemente inclinada (fig. 1c). La nota fue escrita por el Dr. Wolfgang Haberland, en ese entonces jefe del departamento de las Américas del museo, y en ella afirma que la pieza es de una toba andesítica descompuesta de color rojo, que proviene de "Alto Vassol, río Coquimbo" y que sería de la fase Molle II (0-600 DC). En sus propias palabras:

Este cuenco de piedra único tiene la forma de una balsa hecha de dos cueros inflados, como fueron utilizadas en el siglo pasado por el chango en la costa norte chilena. Encaramado en los extremos doblados del bote, siempre un hombre. El pequeño bastón en sus manos seguramente debe simbolizar los remos con los que se movió esta nave. Los peces son importantes a ambos lados de la balsa. Se reproducen dos especies (Diodon hystrix y Graus nigra). El interior, que está empotrado en contraste con la balsa real, muestra que no es una escultura 'libre' sino un contenedor. Que ella sirvió para propósitos religiosos es una conjetura (Haberland 1984: 335; la traducción es mía).
En 1986 dos publicaciones vuelven sobre la balsa, esta vez exhibiendo las primeras fotografías del objeto en la literatura chilena. José Berenguer, curador en jefe del Museo Chileno de Arte Precolombino, testifica que el museo obtuvo la fotografía de la pieza luego de contactar al director del Hamburgisches Museum für Völkerkunde. Paradojalmente, no se trató de una nueva fotografía del objeto, sino de la misma ya publicada en 1953 por Hans Becher. La imagen, que ya tenía en aquel entonces al menos 33 años de antigüedad, fue usada en el libro de Gonzalo Ampuero Diaguitas. Pueblos del norte verde (1986) editado por el museo (fig. 1d), y al mismo tiempo en el artículo de Lautaro Núñez (1986) Balsas prehistóricas del litoral chileno, publicado en el primer número del Boletín de la misma institución (fig. 1e). Mientras en el libro solo se expone la fotografía de la balsa, en el artículo de Lautaro Núñez se ofrece una breve descripción basada en lo que ya había presentado Gualterio Looser (1960) y Hans Becher (1953) -aunque esta última referencia no aparece en la bibliografía del autor, por lo que probablemente nunca se leyó directamente-. Lautaro Núñez relata que la pieza sería de una toba andesítica y que provendría de Altovalsol, al margen norte del río Coquimbo. La mención a la balsa termina con una nota del editor que detalla un poco más el origen de esta información, facilitada por Wolfgang Haberland.

Como parte de la exposición Diaguita, señores del Norte Verde, del año 1986, el Museo Chileno de Arte Precolombino decide fabricar una réplica de la balsa para exhibirla a los visitantes. La reproducción fue hecha sobre yeso, de color blanquecino y a una escala notoriamente mayor a la original, cuyo efecto tanto en volumen como en color la hacía más imponente ante los espectadores. Dos fotografías de esta pieza fueron publicadas posteriormente en 2011 como parte del libro Compartiendo memoria: 30 años del Museo Chileno de Arte Precolombino (fig. 1g).

José Berenguer vuelve nuevamente a la balsa en 2008, en el catálogo de la exposición Pescadores en la niebla, del Museo Chileno de Arte Precolombino. En esta ocasión reafirma datos ya conocidos, como el hecho de que estaba tallada en andesita, que procede de la Región de Coquimbo y que sería de la fase Inka-Diaguita. Agrega que la pieza está compuesta de dos tripulantes, uno sentado en proa y otro en popa, junto a cuatro peces colgando por la borda. Para cerrar, relativiza el hecho de que se trate de una balsa de cuero de lobo y 
abre la posibilidad de que sea una de haces de totora de dos cuerpos, poniendo el énfasis en la capacidad de carga de la nave. Repitiendo el ejercicio anterior, el museo decidió hacer una segunda réplica de la balsa, esta vez del mismo tamaño que la original y tallada sobre piedra, aunque de una materia prima de color gris. Esta reproducción se exhibe hoy en las vitrinas del Museo Arqueológico de La Serena.

En 2009, Patricio Núñez y Rodolfo Contreras publican un breve artículo sobre una desconocida miniatura de embarcación recuperada por Augusto Capdeville en Punta Morada, Taltal. El hallazgo fue parcial, pues no encontraron la pieza sino un dibujo de ella en un antiguo documento que fue donado al museo por sus herederos. En un acápite final de la revista dedicado a las figuras a color, los autores presentan una fotografía a color de la balsa de piedra de Altovalsol tomada desde la vitrina del museo de Hamburgo por Patricio Núñez en uno de sus viajes. Lamentablemente no hay referencias a la balsa en todo el artículo, solo la fotografía anexa que, aunque borrosa, deja entrever que su color era claramente rojo.

Finalmente, en 2016 un nuevo catálogo del Museo Chileno de Arte Precolombino rememora la balsa de piedra -a esta altura, ícono del museo capitalino-. En el primer capítulo de El arte de ser Diaguita, Gloria Cabello elabora una Breve historia Diaguita antes del arribo de los españoles, en la cual la escultura en piedra de Altovalsol reaparece, aunque ahora reemplazada por una fotografía de la segunda réplica tallada en 2008. En la imagen se aprecia la balsa completamente de perfil y su color es gris (fig. 1h).

El largo derrotero de esta singular escultura de piedra a través de las biografías escritas demuestra cómo un objeto ausente fue reemplazado por descripciones, dibujos, fotografías, ilustraciones y réplicas hechas desde las fotografías, e incluso desde las fotografías de las réplicas. El objeto original, distante a más de 12.000 kilómetros de su lugar de origen, fue lentamente sustituido usando diferentes soportes materiales para llenar el vacío de sentido que dejó en la prehistoria local. Desde la primera referencia al objeto su valor fue creciendo, al igual que la necesidad de exhibir mejores suplentes en una búsqueda constante por corporizarlo. A lo largo de esta cadena de reproducciones, eslabón por eslabón, ocurrieron transformaciones de la pieza original que fueron construyendo un objeto virtual, o varios objetos virtuales, que se volvieron diferentes al que le dio vida. Una mutación de la idea, del recuerdo y de la memoria del objeto, debido a la acumulación de sutiles imperfecciones en cada una de sus reproducciones, tanto visuales como escritas. La sumatoria que da cuerpo al objeto virtual esconde tras de sí, en la penumbra del desconocimiento, todos los procesos de evolución artística y los gestos de creación de su diseño. La mayor parte de ellos inconscientes, pero responsables de la obra final -o más bien, de las obras finales-.

El mejor ejemplo de este fenómeno yace en la fotografía de la réplica de la balsa del año 2016 (fig. 1h). Se la exhibe de color gris, tal como en la primera fotografía publicada en 1953, reproducida una y otra vez por más de cincuenta años hasta 2009. Si bien la pieza original posee un color rojo intenso, debido a que la fotografía de aquellos años era en blanco y negro, en el imaginario el objeto virtual se construyó de color gris consecuencia de las tecnologías fotográficas y las capacidades de impresión de ese tiempo. Cuando se decidió hacer la segunda réplica, esta fue tallada sobre una roca grisácea que se acomoda bien a la imagen de aquellas fotografías. La copia en piedra de color gris vuelve a representarse ahora a través de nuevas fotografías a color que la muestran posando en una posición similar y luciendo un cuerpo gris. La transmutación del color se vio reforzada también por la cadena de referencias a la materia prima de la escultura, siempre de andesita, asumiendo que era gris, tal como en las fotografías. Solo Hans Becher (1953), Wolfgang Haberland (1984) y Patricio Núñez (2009), únicos testigos presenciales de la escultura de todos sus biógrafos, especifican que ella tiene un color rojo. En Chile, Gualterio Looser fue el exclusivo lector de las fuentes primarias, mientras que los biógrafos posteriores se contentaron con su breve y selectiva mención sin volver a los textos originales.

\section{DOCTOR RICARDO SCHWENN}

Si desconocemos la historia de algunos arqueólogos chilenos, no es extraño que la vida de la mayoría de los coleccionistas de piezas precolombinas sea prácticamente un misterio. Ricardo Schwenn fue un afamado excavador de cementerios prehispánicos y devoto a los objetos antiguos de La Serena, en la Región de Coquimbo, durante la primera mitad del siglo xx. Lamentablemente nunca publicó sus hallazgos ni documentó personalmente las piezas de su colección. Tampoco hay información acerca de la existencia de cuadernos de campo o apuntes 
escritos en museos o en poder de sus familiares. Por lo tanto, los únicos testimonios disponibles hoy para reconstruir en parte su vida son algunos informes del área de la salud, reseñas de arqueólogos contemporáneos con los cuales compartió, los inventarios de los museos donde están hoy depositadas sus colecciones, el archivo de correspondencias del Museum am Rothenbaum, y bueno, los mismos objetos arqueológicos que pasaron por sus manos. A través de fragmentos de todas estas fuentes se puede reconstruir un perfil preliminar de su vida, en especial con relación a los sitios arqueológicos que intervino, el tipo de objetos que atesoraba, sus compradores y los museos que hoy guardan su colección.

La Memoria, plan de estudios i reglamento del Instituto Superior de Educación Física, del año 1918, señala que Ricardo Schwenn von Sichart habría sido uno de los oficiales del Ejército que recibió el Diploma de Instructor de Jimnasia en la ciudad de Santiago. En 1921 egresa como bachiller en Medicina i Farmacia de la Universidad de Chile, y cuatro años más tarde obtiene el grado de médico cirujano en la misma casa de estudios (Anónimo 1921, 1925). En una carta con fecha del 6 de julio de $1936^{4}$ se indica que Schwenn había sido doctor del Regimiento de Artillería número 2 de La Serena, y más adelante, un médico muy respetado y popular en la ciudad. La Guía Médica Nacional de 1959 lo sitúa en ese año aún ejerciendo activamente la profesión en la misma ciudad. Actualmente, algunas calles llevan en su honor su nombre en La Serena y El Molle (en el valle del Elqui). En este último lugar tuvo al parecer una casa de descanso que sirvió de base a sus excursiones arqueológicas.

En el campo de la arqueología, la información es casi tan fragmentaria como fuera de él. De acuerdo a Ricardo Latcham (1940), Schwenn realizó numerosas excavaciones en el sector de Los Molles y habría poseído al menos colecciones arqueológicas provenientes de la localidad de Cachiyuyo y sus alrededores. Del mismo texto se desprende que Schwenn conocía bien los postulados de Francisco Cornely sobre la prehistoria local. Es indudable que alguna clase de relación existía entre estos dos últimos personajes, en primer lugar porque ambos tenían filiación germana ${ }^{5}$ y vivían en la misma ciudad, por lo que probablemente compartieron en los círculos de inmigrantes alemanes. Pero también porque el fundador del Museo Arqueológico de La Serena nombra a Schwenn en sus publicaciones, en especial para referirse a ciertos objetos clave que él conservaba o a yacimientos que había excavado (Cornely 19471949, 1949, 1956). En uno de ellos, Francisco Cornely (1949) estudia y dibuja una serie de piezas cerámicas propiedad de Ricardo Schwenn, todas de época incaica y provenientes de alguno de los cementerios de área de Altovalsol. Desde Francisco Cornely se desprende que Schwenn habría excavado al menos en Almirante Latorre, Puclaro y Altovalsol.

Los escritos de Jorge Iribarren $(1957,1962,1971)^{6}$ también develan a Ricardo Schwenn. En sus propias palabras:

\footnotetext{
Esta persona, por varios años estuvo haciendo excavaciones en diversos cementerios indígenas de los alrededores de La Serena y en otros lugares del Valle de Elqui, sin llevar anotaciones y con métodos técnicos precarios. Sus colecciones fueron adquiridas por algunos museos europeos, coleccionistas particulares y el Museo de La Serena. Este, en su primera formación, obtuvo por compra una considerable cantidad de piezas cerámicas, principalmente de mucho valor estético aunque desposeídas de su contexto cultural. Las piezas de esa colección, en muy alto porcentaje, están relacionadas con la Cultura Diaguita Chilena (Iribarren 1971: 30).
}

En el mismo texto, Jorge Iribarren afirma que el Museo Arqueológico de La Serena adquirió alrededor de 750 objetos precolombinos a Ricardo Schwenn, algunos de los cuales vienen dibujados y referenciados en su artículo; todos de proveniencia desconocida. La compra de la colección completa ocurrió el 4 de julio de 1950 usando fondos fiscales y comprendía piezas recuperadas por el mismo Ricardo Schwenn y otras conseguidas por pagos a distintos coleccionistas (Gómez 2009). Los antiguos inventarios del museo confirman la existencia de las piezas que se conservan todavía en una misma colección que lleva el nombre del doctor. Llama la atención que ese mismo año Ricardo Schwenn ingresa al directorio de la Sociedad Arqueológica de La Serena, tal vez como parte de la negociación en la venta de la colección o como agradecimiento por el gesto.

Décadas después, Gastón Castillo e Ivo Kuzmanic estudian las antiguas colecciones del Museo Arqueológico de La Serena y se topan con el problema de la falta de contexto e información de algunos materiales. Una de las causas, aseguran ellos, era que el doctor Schwenn tenía la costumbre "de desmembrar las colecciones particulares de un sitio y formar colecciones misceláneas con materiales provenientes de diversos sitios y épocas culturales y repartirlas ya sea en donación o en venta a los Museos" (Castillo \& Kuzmanic 1981: 152). 
Sabemos también que su colección era bastante mayor y que vendió obras a diferentes museos en el extranjero. Así, por ejemplo, en el archivo del Museum am Rothenbaum existe un documento de diez páginas con fecha del 1 de septiembre de 1936 que corresponde a un inventario de objetos que en ese entonces componían la colección arqueológica de Ricardo Schwenn, en total 882 unidades. En el listado, los artefactos vienen numerados y separados por sitio: Compañía Baja ( ${ }^{\circ}$ 31), Peñuelas ( $\mathrm{N}^{\circ} 10$ ), Punta Teatinos ( $\mathrm{N}^{\circ} 7$ ), Arrayán ( No 1), Lengua de Vaca (№ 5), San Julián ( No 3), Punta de Piedra (No 8), El Pingo (No 3), Vallenar ( $\mathrm{N}^{\circ}$ 5), La Serena ( $\left.N^{\circ} 14\right)$, Atacama y Chuquicamata ( $\left.N^{\circ} 15\right)$. En cada caso especifica brevemente los contextos de donde provienen las piezas, salvo en el caso de "La Serena", donde dice textual que esas piezas él las compró y que no conoce su procedencia. Otro conjunto de artefactos continúa la lista, esta vez no ordenados por localidades, sino por materialidad, separados por objetos de piedra, de hueso y de metal.

Existen más antecedentes en Estados Unidos. Mary Shepherd Slusser afirma en su tesis doctoral (1950) que todos los artefactos arqueológicos del centro norte de Chile de la Crocker Collection del American Museum of Natural History de Nueva York proceden también de manos del doctor Schwenn. Este último habría vendido alrededor de 260 objetos prehispánicos al Sr. Templeton Crocker, quien luego las habría donado junto al resto de su colección al museo. Destacan vasijas cerámicas Diaguita, Inca y una Molle en el inventario de piezas, además de cabezales líticos, arpones de hueso, barbas, anzuelos, pesas, espátulas del complejo Rapé, collares y colgantes de piedra y mineral verde, junto a objetos de metal, como placas, discos, anillos, pinzas, aros y anzuelos. Jorge Iribarren (1957: 16) también atestigua que Ricardo Schwenn vendió una de sus colecciones a un museo en Estados Unidos, en la cual había, al menos, piezas del cementerio de El Olivar - probablemente es la misma a la que se refiere Mary S. Slusser pocos años antes-.

En este enmarañado escenario se vio inserta la balsa de piedra. Un objeto más entre cientos que pasaron de mano en mano entre coleccionistas, arqueólogos, compradores, tasadores y curiosos. Trazar la historia de estas colecciones es una tarea por realizar, considerando que es parte importante de la biografía de los objetos que la componen (Alberti 2005, Gosden \& Marshall 1999, Hoskins 2006, Kopytof 1991), más aún cuando algunas de estas piezas se convierten con el paso del tiempo en íconos y emblemas de la arqueología local, referidas constantemente, reproducidas una y otra vez en distintos soportes, convirtiéndose en elementos claves de la construcción de la prehistoria.

\section{EL DERROTERO DE UNA BALSA DE PIEDRA}

En una carta de Ricardo Schwenn dirigida a Franz Termer, en ese entonces director de la sección de América del Hamburgisches Museum für Völkerkunde, fechada el 15 de agosto de 1952, el coleccionista chileno narra la forma en que recibió la escultura y su proveniencia. Una mañana una joven de 14 años entró a su consultorio en La Serena portando en sus manos la balsa. A primera vista pensó que se trataba de una pieza moderna, pero al examinarla con más detalle se dio cuenta de la singularidad del objeto. Según la niña, la particular obra fue encontrada en un arado al lado norte del río Coquimbo en el "Alto Valsol", en un "potrero libre, no en una tumba". Desafortunadamente la carta no dice cuándo ocurre este hecho, sin embargo, es muy probable que sucediera entre 1936 y 1939 (más adelante explicaré por qué).

Ricardo Schwenn comienza las negociaciones de venta de su colección al Hamburgisches Museum für Völkerkunde el primer semestre de 1936. El tire y afloje bilateral para acordar el precio toma algunos meses. En un comienzo pidió 16.000 marcos del Tercer Reich (RM), pero por falta de fondos del museo lo redujo a $6000 \mathrm{RM}$, hasta acordar un total de 5000 RM. En aquellos años, las arcas alemanas no podían permitirse grandes despilfarros de dinero considerando el momento que se vivía y los planes de sus gobernantes. Es por esto que la colección chilena es finalmente comprada por una asociación de tres instituciones, los museos etnográficos de Hamburgo, Múnich y Berlín. El primero pagó 2000 RM, el segundo 3000 RM y el tercero cedió algunos objetos de sus propias colecciones a cambio de una parte de la chilena. No existe información detallada acerca de cómo se realizó la distribución de las piezas, pero sí que los tres museos almacenan aún hoy una porción del conjunto original. Según el inventario enviado por el mismo Ricardo Schwenn, la colección vendida se componía de 882 objetos. Luego de concertar montos y saldar cuentas, la colección fue transportada en barco directamente hacia Hamburgo, primero a su puerto libre y más tarde al museo etnográfico de la ciudad. Paso seguido se trasladó íntegramente en tren hasta Berlín donde fue 
dividida y repartida entre los tres museos involucrados en la compra. La colección, ahora desmembrada, volvió a viajar hacia las instituciones de destino cruzando la Alemania del Tercer Reich.

Pero la balsa de piedra no iba en la carga de este viaje. Lo sabemos bien porque no aparece en el inventario de piezas de 1936, pero más importante aún, porque viene individualizada en cartas posteriores que adelantan un segundo envío de objetos arqueológicos al Hamburgisches Museum für Völkerkunde en 1939. Lo más probable es que la irrupción de la niña con la escultura en el consultorio del doctor ocurriera justo entre esos dos años. En esta nueva oportunidad, Ricardo Schwenn le pide a su amigo R. Kämer, dueño de una farmacia en La Serena, que lleve 19 piezas para intentar venderlas a Alemania. Desgraciadamente, ese mismo año estalla la Segunda Guerra Mundial y toda comunicación entre las partes se interrumpe -en el archivo no hay cartas o telegramas sino hasta 1946-. Todo parece indicar que la balsa junto con otros 13 objetos llegaron sanos y salvos al museo - de los cinco restantes nada se sabe-, ya que en una carta firmada por Max Uhle el 2 de agosto de 1939, este asegura haber visto y analizado las obras, certificando su autenticidad. Max Uhle quedó sorprendido por la balsa, calificándola como un objeto único en su tipo. Aconseja al museo no dejarla ir luego de la oferta de compra, aun cuando le pidieran 2000 RM por ella. Tanto es su interés que abiertamente ofrece comprarla él mismo si es que el museo decide no hacerlo.

Finalmente, Ricardo Schwenn entrega los objetos como donación al museo sin pedir dinero a cambio, a modo de agradecimiento por cuidar de ellos durante la guerra. Exige, no obstante, que le sean devueltas dos jarras Diaguita y la balsa de piedra, ya que durante la Segunda Guerra Mundial fue nombrado Director de la Sociedad Arqueológica de La Serena, y considera un deber moral su repatriación. La demanda no tiene respuesta en la Alemania abatida -imagino que las preocupaciones habrán sido otras en aquellos años-. Envía en avión a su amigo Hans Cordsen con un poder notarial a reclamar los objetos, pero tampoco logra recuperarlos. Las últimas cartas del archivo datan de fines de agosto de 1951 y muestran a un Schwenn convencido en recuperarlas, cosa que nunca ocurrió.

La mañana del primer lunes de julio de 1962, Franz Termer llegó como todos los días al Hamburgisches Museum für Völkerkunde. Recorría los salones paseando frente a las vitrinas cuando, en la exhibición del ala americana, descubrió que la balsa de piedra había sido robada. Alguien levantó el pesado vidrio que resguardaba la pieza, la escondió bajo su abrigo y logró escapar sin ser visto por los únicos dos guardias que en ese entonces vigilaban las 15 salas del enorme museo. El hecho causó conmoción en Hamburgo y fue noticia en los principales periódicos de la época. El 4 de julio, el Die Welt publicaba una nota titulada "Robo de arte en el museo de etnología. El valioso cuenco de piedra chileno desapareció: el culpable hasta el momento sigue sin rastro". El ejemplar de Das Bild pregonaba ese día con letras grandes y subrayado en rojo " Robo de arte! Preciosa presa: un cuenco de 1000 años". El Hamburger Abendblatt no se quedó atrás y su encabezado indicaba: "Precioso cuenco de piedra robado del Museo de Etnología. Los delincuentes aún se desconocen / ¿Fue un coleccionista?". Dos de las tres notas de prensa exhiben una fotografía del doctor Haberland levantando la gran vitrina cuadrada, de aspecto pesado y robusto en la imagen, reproduciendo el gesto que posiblemente realizaron las o los delincuentes durante el robo. Las tres, por su parte, imprimieron además la misma ilustración de la escultura, de perfil, mirando hacia la izquierda y en escala de grises. Una de ellas enseña también un boceto frontal de la balsa tripulada.

Según recortes de prensa, la escultura fue encontrada el 13 de julio envuelta en papel de periódico dentro de una caja fuerte del tren federal de Hamburgo. Nunca se supo la identidad de los responsables. Desde ese entonces la pieza se resguardó con máxima seguridad en el museo. A partir del 6 de noviembre de 1975 volvió a ser expuesta ahora en la llamada Goldkammer o Sala de Oro, donde se exhibían -y custodiaban- las obras de mayor valor que poseía la institución, en especial objetos de oro -por eso el nombre de la sección-. Ahí permaneció hasta el 15 de abril de 2005. Desde 2006, la escultura posa sobre una pequeña tarima en el centro de la primera vitrina de la exposición permanente "Tesoros Andinos". Figura como la estrella del preludio al exuberante mundo de los Andes, antesala de los escaparates que exhiben decenas de vasijas Nazca y Paracas. En el mismo altar de terciopelo azul de la balsa, aunque rodeándola en los márgenes del cuadro visual, cuelgan arpones, tabletas de madera, pesas de piedra, cuchillos, anzuelos de concha, cucharas modeladas de hueso, tubos para inhalar, ganchos de atalaje, tres tembetás, cinco enormes cuchillos taltaloides y cuatro vasijas decoradas Diaguita. ${ }^{8}$ Los objetos radiados, todos de gran belleza 


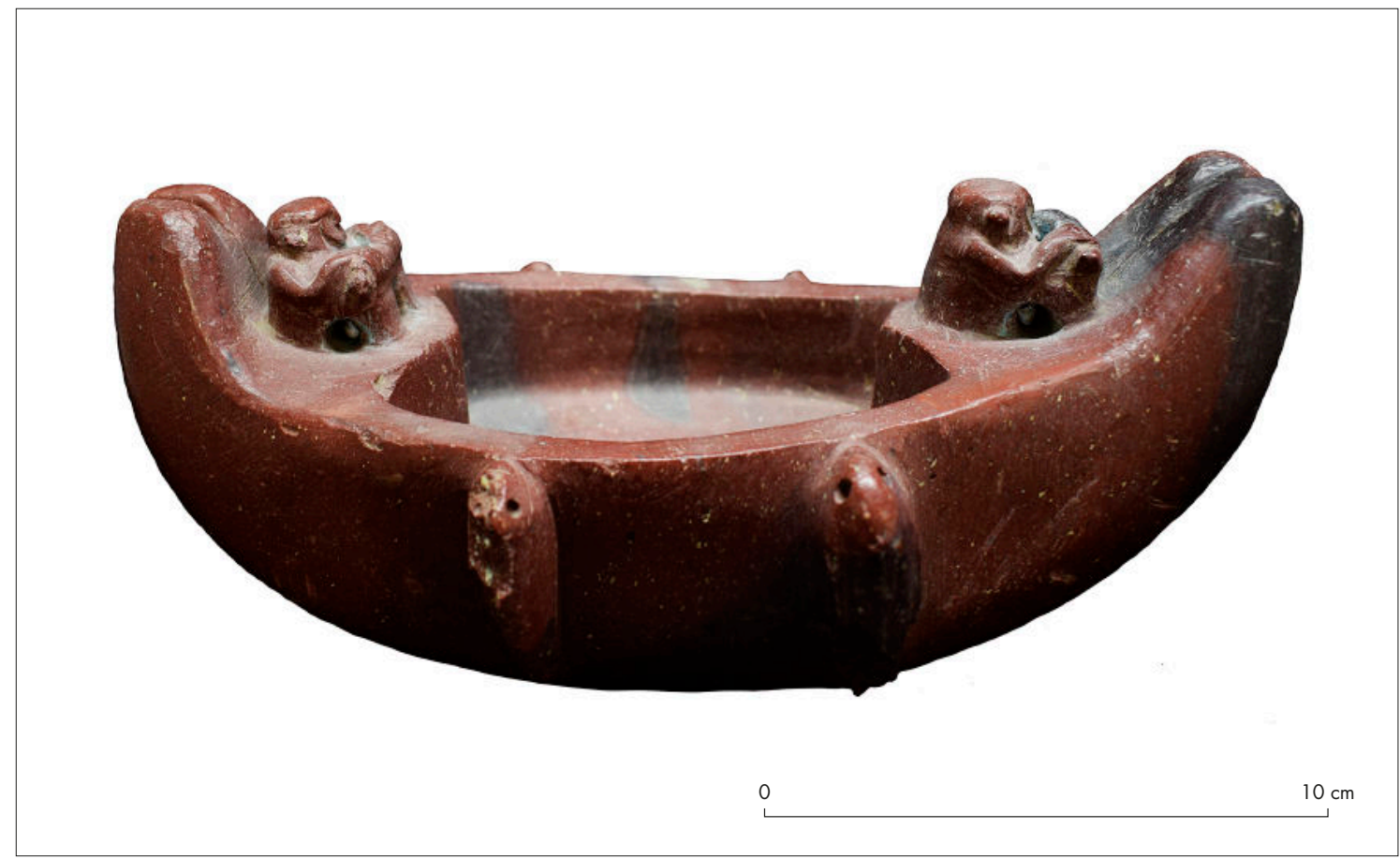

Figura 2. Perfil de la escultura de la balsa. Figure 2. Profile of the raft sculpture.

y calidad artística, solo adornan la composición de una imagen museográfica en la cual la balsa es la gran protagonista; central y magnífica, todos los haces de luz apuntan hacia ella.

\section{DAS STEINBOOT}

La escultura posee un lustre a la vez brillante y oscuro, apariencia visual que se exaltó en el sombrío cuarto abovedado y sin ventanas donde examiné la pieza en el subterráneo del Museum am Rothenbaum (fig. 2). Es de un color rojo mate e intenso, con vetas negruzcas, moteado de pequeñas inclusiones grises y grandes lóbulos blanquecinos propios del tipo de piedra. La textura de su superficie es suave y bruñida, salvo en ciertos rincones donde aplicar el pulido fue imposible por los ángulos y recovecos impuestos por la forma. La roca parece algo talcosa y moldeable, de una solidez fingida que disimula su idoneidad para un labrado fino y delicado de lo cual la escultura es fiel evidencia.

Es un objeto denso y masivo, de casi tres kilogramos de peso. Un macizo bloque que sin embargo se manipula con cautela y cuidado, como si fuera de cristal por su calidad de obra de arte. La proa y la popa de la balsa delimitan su longitud, en total 25,6 centímetros. A lo ancho, entre babor y estribor de la nave hay 14,5 centímetros. Esto lo convierte en un objeto más bien alargado y fusiforme, de cuerpo engrosado en el centro, con tal de ampliar el espacio disponible para la cavidad que sirve de contenedor, ${ }^{9}$ a modo de cuenco (fig. 3). La forma del hueco es singular y no responde a geometrías convencionales. Es claro, por esto, que la pieza no es solo la representación de una balsa, sino también un objeto que sirve para guardar, separar y juntar elementos en su interior. Esta función transformó el cuerpo de la escultura, ensanchándola considerablemente en su centro respecto de la forma tradicional de este tipo de embarcaciones.

Todo el volumen de la imagen se sostiene sobre dos elementos fundacionales, ambos los más vistosos y masivos de la pieza, los odres de la balsa. Un surco medial recorre de extremo a extremo la nave a través del casco delimitando ambas unidades composicionales. Además, tanto en popa como en proa, la división entre los odres se acentúa al estrecharse su forma y separarse poco antes de su extremo final, en la parte más alta de la balsa. Si bien los odres son curvos y con forma de 
media luna, la base posee una leve plataforma que le permite mantenerse estable sobre una superficie plana. Este debió ser su punto de apoyo y la manera en la cual se disponía el objeto, tal como se hace aún hoy dentro de la vitrina del museo. La sección transversal de los odres nunca es completamente circular, y a lo largo de ellas se aprecian suaves aristas longitudinales, en especial en los bordes de la cubierta y en los extremos de la pieza. Únicamente los márgenes del contenedor central poseen aristas rectas, marcadas y agudas.

Algunos de los relatos e ilustraciones más conocidos sobre la balsa de cuero de lobo marino aseguran que ambos odres se disponían formando un compás, juntos en proa y abiertos hacia popa (p.e., Feuillée 1714, Frezier 1717, Gay 1854, Miers 1826). Quienes han investigado en épocas posteriores este sofisticado medio de navegación llegan a conclusiones similares, bajo el argumento de que es el mejor diseño para romper el oleaje, el cabotaje en la orilla y acercarse a las rocas (p.e., Álvarez 1999, Latcham 1915, Looser 1938, 1960, Lothrop 1932, Núñez 1986). Sin embargo, existen otras narraciones que describen balsas confeccionadas con odres paralelos y amarrados entre sí, ampliando la diversidad de soluciones técnicas usadas en el pasado (p.e., Bresson 1875, Duplessis 2003, Marcoy 1875, Niemeyer 1965-1966, Philippi 1860). Mientras la forma triangular de la balsa define tajantemente cuál es la proa y cuál la popa, en el modelo de odres paralelos la orientación de la nave es intercambiable, dando otra versatilidad a la embarcación (Ballester \& San Francisco 2017). En el caso de la escultura en piedra, se dispusieron ambos odres uno al costado del otro, sin aberturas en los extremos. Tiene, en este sentido, una composición simétrica, si comparamos el odre de estribor con el de babor, sirviendo su eje central y longitudinal como plano especular.

Algo similar ocurre con las alturas relativas entre proa y popa. De perfil, la embarcación es a primera vista simétrica, pero al observarla con atención y hacer rápidas medidas se descubre que la proa es siete milímetros más alta que la popa. Cuestión que también es discutida entre los estudiosos de las balsas de cuero de lobo marino, pues la evidencia histórica muestra diversas soluciones técnicas y de diseño, con proas más altas, popas más elevadas y ambas parejas a un mismo nivel (p.e., Álvarez 1999, Ballester \& San Francisco 2017, Niemeyer 1965-1966). Las diferencias pueden corresponder a mejoras técnicas para el control del oleaje $\mathrm{o}$ a soluciones culturales locales, ámbito tecnológico sobre el cual aún no hay consenso.

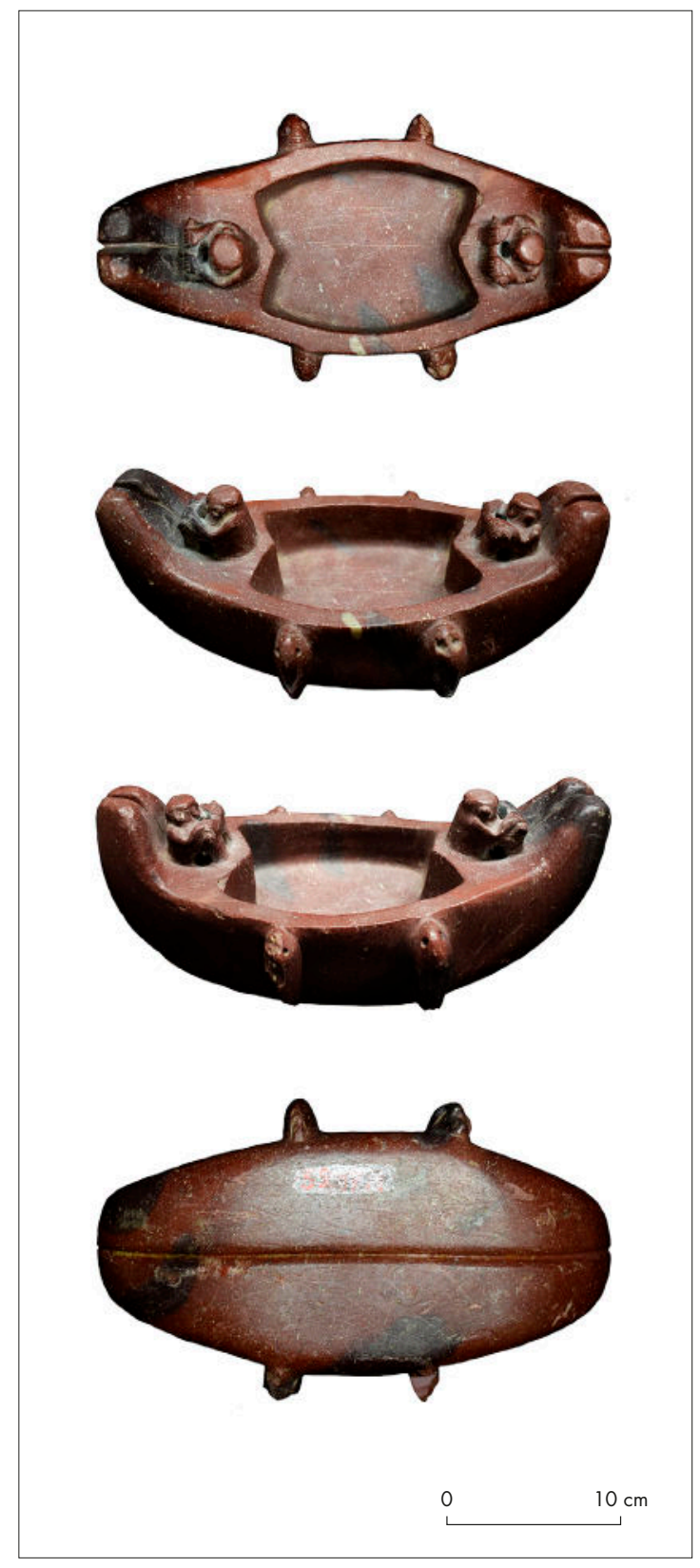

Figura 3. Cuatro vistas de la balsa. Figure 3. Four views of the raft.

La cubierta de la escultura es plana y no se trazó la división entre ambos odres como ocurre en la base de la embarcación. Una plataforma homogénea rodea el espacio central que sirve de contenedor. Sobre ella se alzan ${ }^{10}$ dos personajes antropomorfos labrados y pulidos sobre la misma roca, uno entre la proa y la cavidad, otro entre esta última y la popa (fig. 4). Ambos sujetos tienen 


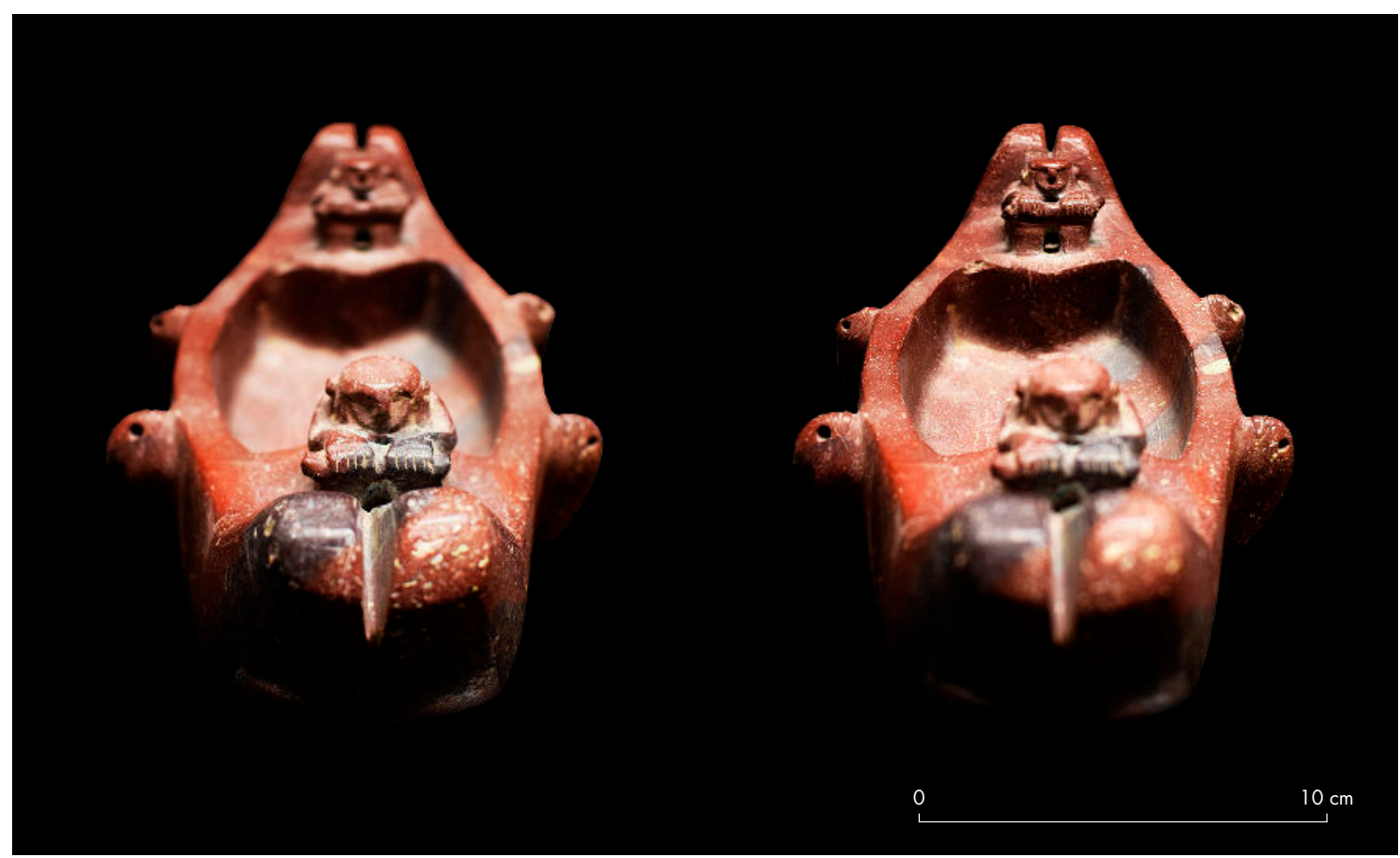

Figura 4. Vista de frente de la balsa con dos puntos de foco. Figure 4. Front view of the raft with two focus points.

exacta postura y apariencia. Comparten un diseño. Uno es reproducción del otro, tal como el odre de estribor es réplica del de babor. Lo único que los diferencia es hacia donde dirigen la mirada respecto de la balsa; el de proa mira hacia el horizonte fuera de la embarcación, mientras el de popa mira hacia el interior -sutil diferencia composicional que revisaremos en detalle más adelante, por ahora quedémonos con los balseros (fig. 5)-.

Ambos están sentados sobre cubierta, con las rodillas flectadas frente al pecho, el torso erguido y las manos sobre las rodillas. Sus cuerpos son toscos, robustos y anchos. ${ }^{11}$ No poseen un cuello marcado. Sus brazos no están estirados, sino semiflectados. Las manos hacia adelante, una paralela a la otra, sostienen un objeto cilíndrico alargado que lamentablemente está fracturado en ambos extremos, los cuales pueden corresponder a los remos de los navegantes. Cada mano fue esculpida empuñando el remo con los cinco dedos hacia adelante grabados por incisión sobre la roca. Los cinco dedos de cada mano están uno al costado del otro, en paralelo, un gesto sumamente interesante considerando que es una postura anatómicamente incorrecta que no distingue la cualidad prensil del pulgar. Ahora bien, la postura de ambos individuos con sus remos en las rodillas denota un carácter pasivo e impávido, sin actividad ni movimiento, en descanso o a la espera del algo. No reman, ni sortean la ola, ni cazan con un arpón; ambos esperan quietos, sentados, en una misma posición mirando hacia el frente.

Bajo las rodillas de ambos sujetos, entre sus pies y asiento, la pieza tiene labrada un canal tubular que cruza de lado a lado. Este conducto parece haber sido especialmente trabajado, ya que su sección es redonda y está muy repasada. El ducto transversal posee dos salidas o entradas adicionales; una en la parte frontal del individuo, entre sus dos pies justo sobre la cubierta de la balsa, y otro en la parte superior entre ambos brazos, delante de su cara y tras el remo. Estas cavidades y túneles generan juegos de luces y sombras que afectan la apariencia de los individuos y varían en función de la iluminación y perspectiva en que miremos la pieza. Si bien podría tratarse de un elemento exclusivamente estético y representacional, no se descarta también que sea un mecanismo diseñado para colgar la escultura usando cordeles que pasen a través de los ductos.

Solamente a uno de los dos balseros le agregaron pies. Al que va sentado en la proa no se los representaron y sus piernas terminan abruptamente sobre la cubierta 

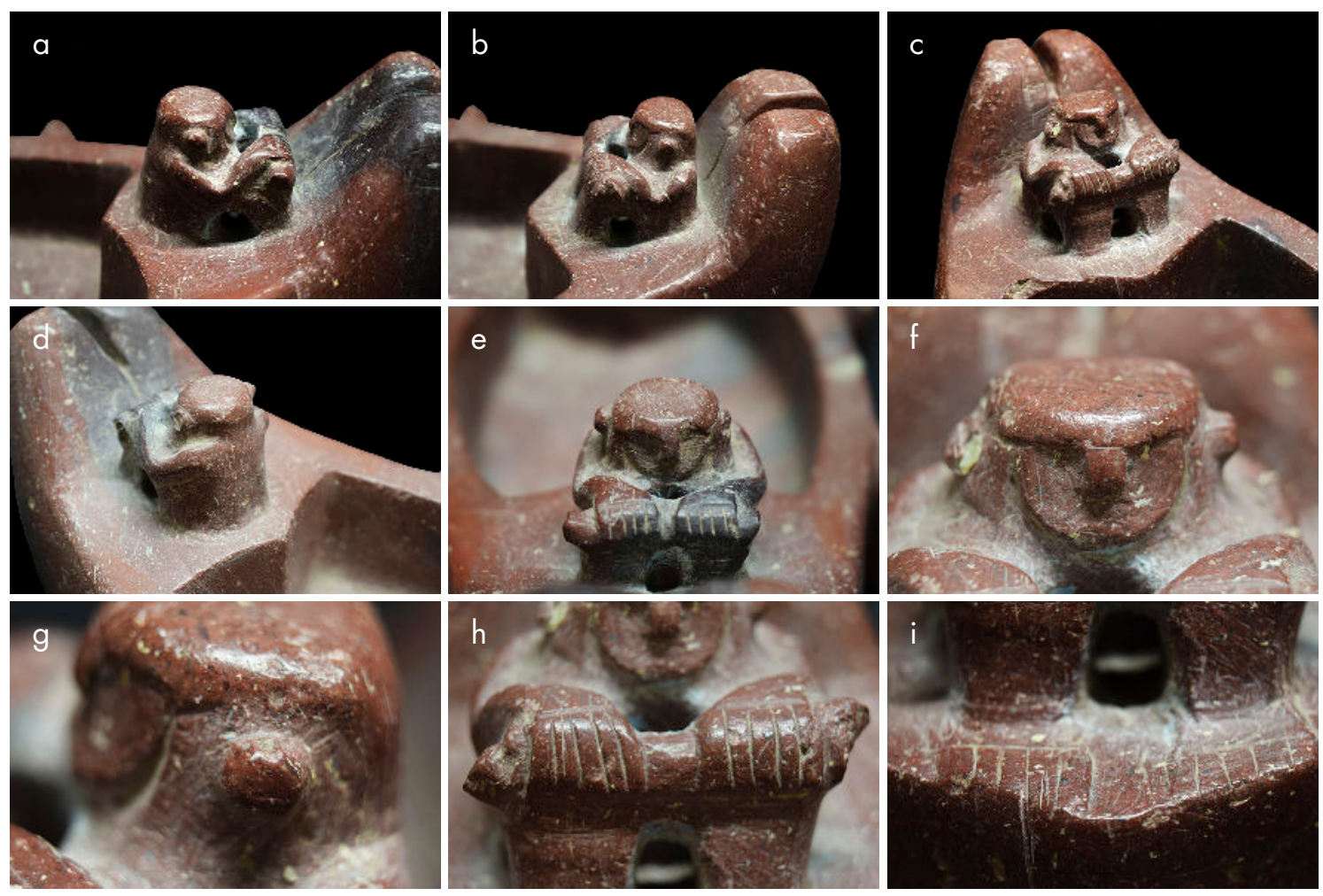

Figura 5. Detalle de los balseros de la escultura. Figure 5. Detail of the raftsmen in the sculpture.

de la balsa justo antes de que el extremo de los odres se levante. El tripulante de popa, por su parte, posee dos claros pies dispuestos inmediatamente al frente de sus piernas. A diferencia del cuerpo, no fueron labrados en volumen, sino grabados por incisión sobre la plataforma de la balsa. Tiene cinco dedos en cada pie, uno al lado del otro, trazados a través de incisiones rectas y finas, lo que le da una forma más bien tosca y cuadriculada. Para diseñarlos aprovecharon el borde de la cavidad central que sirve de límite a la punta de los dedos de cada pie.

La porción superior de cada personaje está dominada en lo visual por sus cabezas. Ambas son desproporcionadamente más grandes en relación al resto del cuerpo. Efecto visual que se ve reforzado por la ausencia de cuellos entre ellas y el tronco, o al menos por la presencia de cuellos cortos y gruesos formados por una línea recta que baja desde la cúspide de la cabeza hasta los hombros. Vista desde la espalda, las cabezas tienen una forma trapezoidal, recta y plana en la parte alta, abriéndose levemente en diagonal hacia los costados, con una base más ancha sobre los hombros. Del bloque de la cabeza sobresalen hacia los costados dos cortas protuberancias cilíndricas que parecen representar las orejas o accesorios. Desde arriba, ambas cabezas tienden a lo circular, aunque el de popa tiene una ligera prominencia frontal que le da un aspecto más bien triangular. De frente, la cara de los sujetos se modela en bajorrelieve extrayendo materia desde las cejas hacia abajo y dejando como testigo la nariz. La fisionomía del rostro se construye gracias a un elemento sobresaliente en forma de $\mathrm{T}$ que perfila por vaciamiento sus cavidades oculares, pómulos y mentón. El contorno facial es horizontal y recto en la parte alta de la cabeza, continúa siguiendo una silueta de forma curva y en U hacia la sección inferior de la cara, rodeando las mejillas hasta la barbilla.

Cuatro peces adornan la escultura en los costados de la embarcación (fig. 6). Fueron labrados en el mismo bloque de roca que el resto de la pieza, como una sola unidad. Dispusieron dos peces a estribor y dos a babor, tal como si estuvieran colgando desde la cubierta, con la boca hacia arriba y las aletas caudales hacia abajo. ${ }^{12}$ Los dos pares de peces están ubicados simétricamente unos al frente de los otros en la parte medial de la nave. Dos de los peces, uno de cada costado, están bastante 


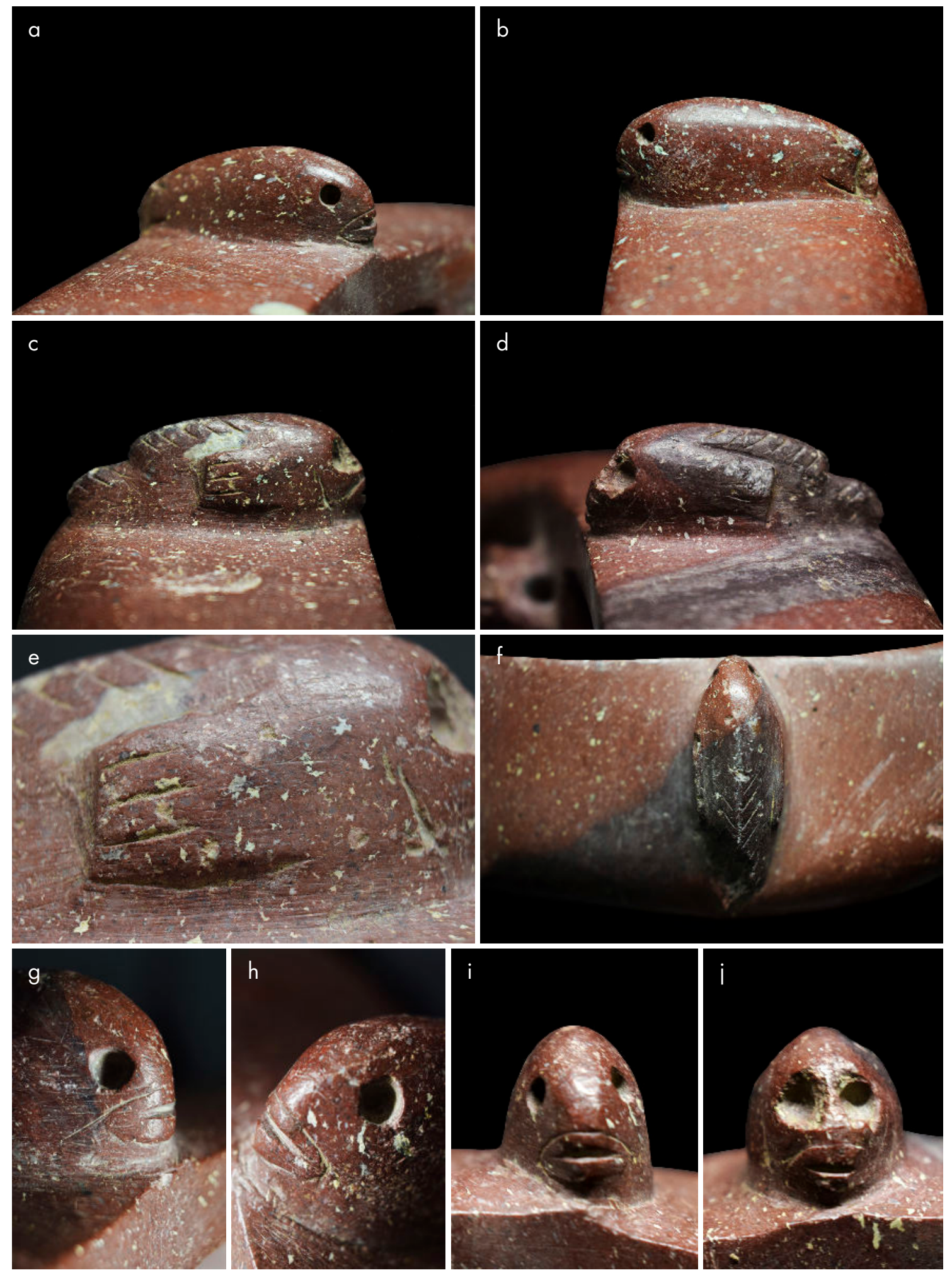

Figura 6. Detalle de los peces de la escultura. Figure 6. Detail of the fish in the sculpture. 
deteriorados por golpes y quebraduras, incluso a uno de ellos le hicieron un corte con sierra para análisis petrográfico a comienzo de los años cincuenta. Lo interesante, no obstante, y tal como lo recalcó Hans Becher (1953), es que representaron dos especies distintas de peces, diferenciados por el nivel de detalle de sus cuerpos: un tipo con aletas dorsales, pectorales y caudales marcadas por modelado en volumen y grabado con incisiones, mientras que el otro tipo posee un cuerpo liso sin rasgos corporales específicos (fig. 6a-f). Becher (1953) y Haberland (1984) fueron más lejos, asegurando que las especies correspondían a Diodon hystrix y Graus nigra, el primero un pez de mares tropicales que no habita en las costas de Chile y el segundo popularmente conocido como vieja. Tal cual veremos en detalle más adelante, a cada lado de la balsa instalaron un pescado de cada tipo, aunque cruzados y en diagonal. Los dos tipos de peces comparten, sin embargo, algunos rasgos anatómicos de representación y técnicas de manufactura. Por un lado, ambos tipos de peces tienen una boca bien definida y labios marcados, grabados con finas incisiones sobre la roca; por otro, sus ojos son circulares, grandes y hechos por perforación de la piedra (fig. $6 \mathrm{~g}-\mathrm{j}$ ).

La aleta caudal completa de uno de los cuatro peces, aquel ubicado a estribor y popa de la balsa, fue cortada con una sierra en enero de 1953 para hacer un análisis petrográfico. El informe señala que la pieza no fue hecha de arcilla cocida o cualquier otro tipo de producto artístico, sino en una roca alcalina vítrea descompuesta. La masa de la roca es ópticamente isotrópica y con débil birrefringencia. Posee óxidos hidratados, una estructura fluida y fragmentos minerales afilados. Los fenocristales de la masa están parcialmente redondeados, son tubulares y en general completamente clorizados. Los óxidos de hierro le impregnan esta coloración rojiza debido a la presencia de hematita. Es muy probable que el tipo de roca analizada corresponda en realidad a una de las variedades de combarbalita características del semiárido chileno, de la cual el laboratorio de la Universidad de Hamburgo no contaba con muestras de referencias para comparar e identificar adecuadamente.

Una retrospectiva a esta descripción densa de la balsa de piedra permite desprender algunos puntos generales importantes sobre su técnica de manufactura. Fue labrada sobre un único bloque de piedra. Mientras el trabajo de tallado en relieve fue pulcro y delicado para dar volúmenes y siluetas redondeadas, curvas y onduladas, ciertos detalles menores, como los dedos de las manos y los pies de los balseros, junto a los labios y las escamas de los peces, fueron grabadas con incisiones delgadas, simples y rectas, para crear figuras cuadrangulares y esquemáticas. En este sentido, sea por decisión cultural o debido a restricciones de su capacidad técnica, hubo distintos resultados en la obra, según se usara el tallado en volumen o el grabado fino. A esto hay que agregar que la pieza fue luego lijada y pulida en la mayor parte de su superficie, entregándole una textura lustrosa y un aspecto brillante.

\section{SIMETRÍAS ESCULTÓRICAS}

Una serie de simetrías rigen el diseño y la composición de los elementos constitutivos de la balsa. En primer lugar, ambos odres son unidades gemelas; idénticos, de igual tamaño y forma, dispuestos en el mismo sentido y orientación, uno al lado del otro. La línea longitudinal que los divide funciona como un espejo o plano de reflexión. Pero este eje proa-popa no solo crea un efecto especular en los odres, sino también lo hace sobre los balseros, ya que los corta justo por el centro en su plano sagital, dejando sus lados izquierdos equivalentes a los derechos. Ningún rasgo distingue sus lateralidades. Lo mismo sucede con el receptáculo interior, cuya singular forma es completamente simétrica si la dividimos por la mitad a lo largo de la escultura. La ubicación de los peces colgando fuera de la borda también se refleja longitudinalmente logrando una coincidencia casi milimétrica (fig. 7a).

No obstante, y como lo adelantamos previamente, la reflexión de los peces se encuentra a su vez invertida debido a una segunda reflexión especular en el plano frontal y medial de la escultura, en el eje babor-estribor. La doble reflexión especular dispone a las dos variedades de peces cruzadas entre sí: el tipo A, en la amura de babor y en la aleta de estribor; el tipo B, en la amura de estribor y la aleta de babor (fig. 7b). Este segundo efecto de espejo genera una simetría también en la balsa, aunque especular simple, ya que la mitad de la proa replica exactamente la mitad de la popa, tal como ocurre además con el contenedor interior de la escultura. Pero la reflexión especular en el plano frontal es quebrada mediante un gesto de diseño. Si fuera completa, ambos balseros estarían o enfrentados mirando hacia el centro de la embarcación u opuestos orientados cada cual hacia horizontes refractarios. Por el contrario, ambos se 


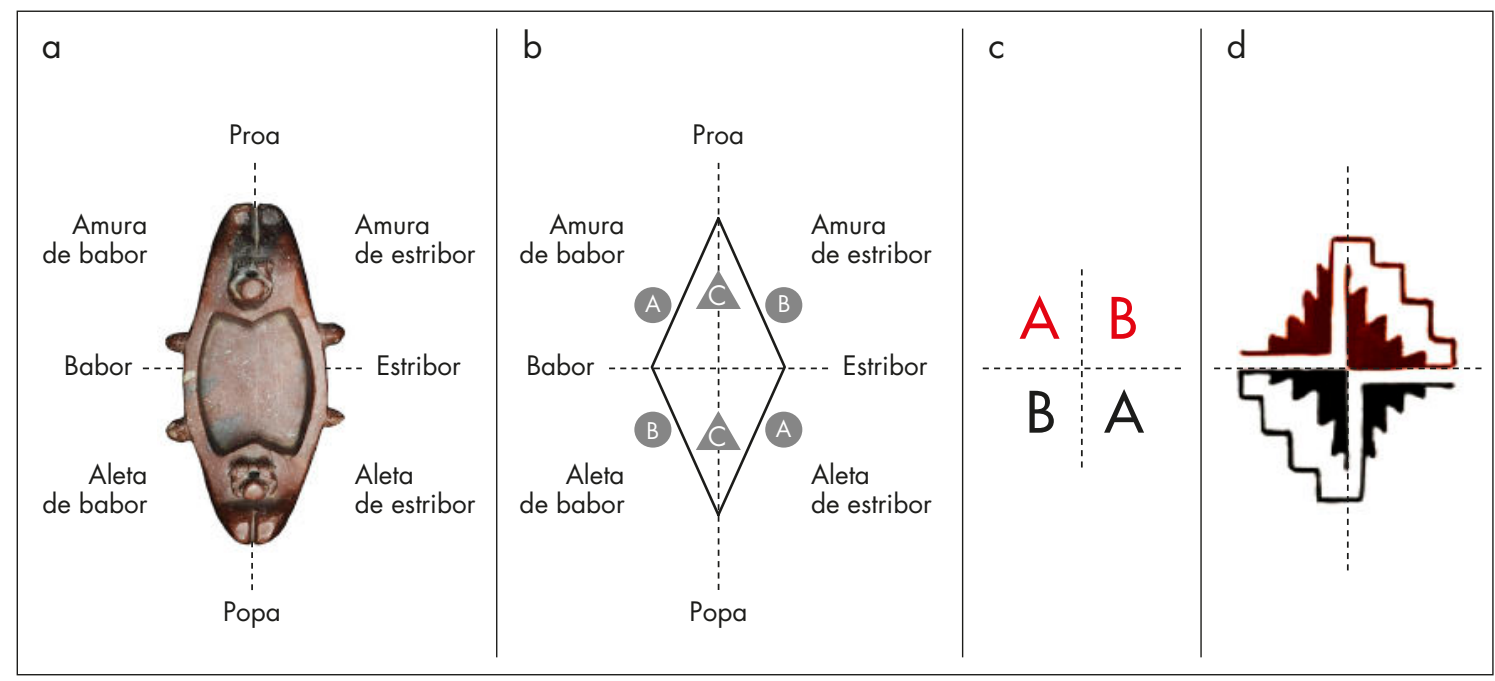

Figura 7. Esquema de simetría de la escultura. Figure 7. Symmetry diagram of the sculpture.

alinean en la misma dirección produciendo un efecto de traslación más que de reflexión. Este sutil detalle de composición crea una distinción entre el plano de proa y el de popa en la imagen reflejada: en el primero el tripulante mira hacia el mar y divisa el destino, en el segundo su acompañante vigila el contenedor y observa hacia el interior de la balsa. Así, la simetría de reflexión especular se complementa de un elemento adicional de distinción que complejiza la ecuación, la cual podría expresarse a través de las siguientes fórmulas (fig. 7c):

$$
\text { pez } 1 / A=\operatorname{pez} 2 / B
$$

balsero proa/balsero popa $=$ mirar afuera $/$ mirar adentro $=$ rojo $/$ negro

$$
\mathrm{A} / \mathrm{B}=\mathrm{B} / \mathrm{A}
$$

A primera vista este juego de simetrías podría parecer azaroso, pero fueron inteligentemente pensadas y cuidadosamente logradas en la roca. Se trata de una lógica de instalaciones, de ideas del volumen, de asociaciones, de cómo se estructura el espacio. En este escenario, los peces dejan de ser solo adornos de la balsa para ser unidades de sentido en su relación con el todo-escultura. Se entiende mejor ahora por qué el gesto de representar dos especies diferentes de peces: la causa de la distinción es crear justamente una doble reflexión especular en el diseño de la pieza.
Las simetrías visuales son habituales en la decoración de la cerámica Diaguita (p.e., Cornejo 1989; Cornely 1947-1949, 1955; González 1998a, 2001, 2006; Troncoso 2005). No debiera sorprendernos entonces encontrar lógicas de ordenamiento análogas en otros objetos, ya que dependen de estructuras inmanentes que rigen las formas de concebir el universo y la asociación de las partes que lo conforman (Washburn 2018). El diseño de la balsa de piedra puede responder de esta manera a estructuras transversales y no ser un mero capricho del escultor. La doble reflexión especular que existe en su diseño de planta es el mismo tipo de simetría que se utiliza con alta frecuencia en los patrones decorativos de la cerámica Diaguita Inca en el semiárido (fig. 7d) (González 1998b, 2004). Más allá de las implicancias temporales de estas simetrías, lo llamativo es que por primera vez se pueden percibir fuera de la pintura y de las expresiones en dos dimensiones, actuando en volúmenes y modelados. Lamentablemente, la escultura de la balsa es una pieza excepcional y no es posible plantear inferencias generales, solo queda como tarea indagar en otros soportes de la cultura material.

\section{CORRELATOS ICONOGRÁFICOS}

Hasta hoy la escultura sigue siendo única, no existe otra igual. Sin embargo, cuando buceamos en viejos hallazgos y sondeamos dentro de notas olvidadas, re- 
saltan una serie de objetos que sirven de comparación y referentes, como puntos de anclaje iconográfico. Quien inauguró las biografías chilenas de la balsa fue también el precursor en estas exploraciones. Antes de enfrentarse por primera vez a ella, Gualterio Looser ya había publicado Objetos líticos ictiomorfos de la arqueología chilena (1935) y casi una década antes Tabletas para tomar rapé del Museo Nacional (1926:21), en los cuales describió en profundidad lo que él define como una tableta en forma de pez hecha de una roca de "arcilla roja muy talcosa perfectamente pulida [...] hallado en Cogotí, departamento de Ovalle, provincia de Coquimbo" (fig. 8a). La temática marina de ambas obras, la misma materia prima y la función compartida como contenedor modelado, evidencia cierto nivel de parentesco entre ellas. En el artículo de 1935 publica un segundo objeto de piedra muy similar al primero (fig. 8b), ya sin definirlo como una tableta, proveniente de la colección privada de Carlos Cruz Montt y de origen desconocido. Su única diferencia con la pieza anterior es que su modelado es mucho más detallado, especialmente en su boca, dientes, labios, accidentes de la cara y los rasgos de las aletas (fig. 8a-d); si no fuera por estos elementos podrían ser perfectamente piezas gemelas.

En 1960 -y republicado en 1983- Gualterio Looser retoma el debate sobre las esculturas de piedra en forma de peces. Junto a las ya mencionadas incorpora dos más prácticamente idénticas, de igual factura y tipo de roca, ambas según él de origen cusqueño, una de ellas expuesta en el Museo Arqueológico del Cusco en Perú y la otra en el Musée Ethnographique de Genève en Suiza (fig. 8e-f). La perspectiva del pez, el receptáculo interior, su forma, cara y aletas son sumamente parecidas. La pieza depositada en Suiza se distingue por su mayor nivel de detalle (fig. 8f), y al hacer un acercamiento a la cara del pez notamos que es prácticamente idéntica a uno de los dos tipos de peces que cuelgan de la balsa de piedra (fig. 6g-h y fig. 8e). Este contenedor fue adquirido, de acuerdo a datos del museo ginebrino, en 1933 de manos de los herederos de Jean-Jacques Schazmann, antiguo cónsul suizo en Chile y gran coleccionista privado de piezas arqueológicas. Si bien buena parte de su colección proviene del Perú, es probable, debido a la similitud de ambos objetos y por haber estado largo tiempo en Chile, que esta pieza depositada en Suiza corresponda a la misma mencionada por Gualterio Looser, de propiedad de Carlos Cruz Montt, quien falleció en 1935 perdiéndose para siempre la pista de la escultura. Un catálogo londinense de venta de obras de arte titulado The Celebrated Carlos Cruz Montt Collection of South American Antiquities, editado por la famosa casa de subastas Sotheby \& Co. en 1939, nos demuestra que a cuatro años de haber fallecido, su colección continuaba vendiéndose por partes alrededor del mundo, ahora en propiedad de su hijo Carlos Cruz-Eyzaguirre. ${ }^{13}$ En dicho catálogo no se encuentra la escultura en forma de pez, por lo que probablemente fue vendida antes de esta fecha. Aunque Gualterio Looser (1983) afirma que la pieza depositada en Suiza proviene del Cusco, una opción muy factible es también que Jean-Jacques Schazmann comprara algunos de los objetos de la colección de Carlos Cruz Montt, lo que explicaría su enorme semejanza. Desafortunadamente, esto es algo que no podemos asegurar.

Tres otras esculturas de piedra con formas de peces publica Gualterio Looser en su artículo (1983), aunque de características relativamente diferentes. Mientras las piezas ya descritas poseen cuerpos alargados y receptáculos cuadrangulares, estas otras son de cuerpo redondo y de cavidad central completamente circular (fig. 8g). Por su forma y el hecho de tener ambos ojos juntos en una misma cara del pez, podría corresponder a un lenguado (Paralichthys microps). Al menos dos de estos tres objetos y uno de los anteriores fueron encontrados en la localidad de Cogotí, al interior de la Región de Coquimbo y cercano a Combarbalá, cuestión que de seguro no es casualidad (Cornely 1947-1949, Iribarren 1973, Looser 1983). Jorge Iribarren visitó en 1956 el sitio de donde provenían estos objetos prehispánicos, en el Potrero La Greda de la Hacienda Puntilla de Cogotí 18 (Looser 1983). En superficie halló trozos de piedra labrada, fragmentos de platos y la misma materia prima con que fueron manufacturadas las esculturas. Según Jorge Iribarren es casi seguro que dicha roca fuera extraída de la falda de un cerro inmediato al sitio donde existen vetas de ese material, una arcilla roja de textura talcosa y blanda, de fácil tallado.

Todo indica que dicha materia prima es combarbalita, una roca de dureza variable, de marcada estructura brechosa y textura con rasgos fluidales, de tonos rojo violáceo, blanco, verde turquesa o combinados (Rosales et al. 1993). Esta roca fue utilizada en época precolombina para labrar distintos tipos de objetos y continúa siendo tallada por los artesanos locales para vender mercancías a turistas (Pérez de Arce 2014). Prefieren para esto los tipos 


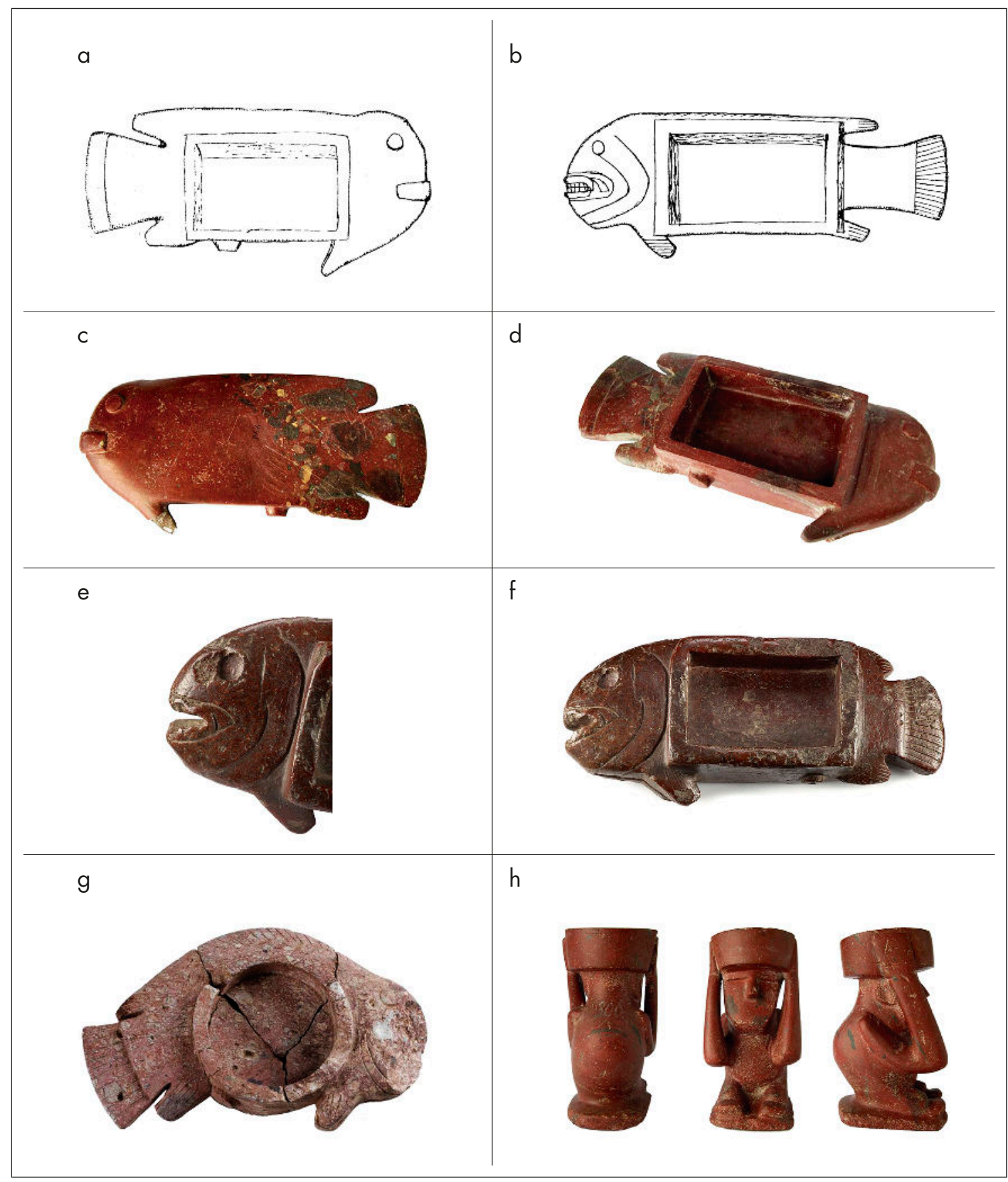

Figura 8. Objetos de piedra relacionados por su forma y materia prima a la balsa: a) objeto en forma de pez, Cogotí 18 (Looser 1935: lam. v, 2); b) objeto en forma de pez, colección Carlos Cruz Montt (Looser 1935: lam. v, 1); c-d) dos vistas de la pieza en forma de pez de Cogotí 18 (MNHN); e-f) dos vistas de un objeto en forma de pez depositado en el Musée Ethnographique de Genève de Suiza (MEG); g) objeto en forma de pez, Hacienda Puntillas en Cogotí, colección R. Villarroel (MALs); h) tres vistas de una escultura antropomorfa con un contenedor sobre la cabeza, Copiapó (MNHN). Figure 8. Stone objects related to the raft by their shape and raw material: a) fish-shaped object, Cogoti 18 (Looser 1936: sheet v, 2); b) fish-shaped object, Carlis Cruz Montt collection (Looser 1936: sheet v, 1); c-d) two views of the fish-shaped piece of Cogoti 18 (MNHN); e-f) two views of a fish-shaped object deposited in the Musée Ethnographique de Genève, Switzerland (MEG); g) fish-shaped object, Hacienda Puntillas in Cogoti, R. Villarroel collection (MALS); h) three views of an anthropomorphic sculpture with container over head, Copiapo (MNHN). 
de menor dureza $(2,5)$, compuestos mayoritariamente de caolinita, alunita y hematita, con muy baja cantidad de sílice. De los cuatro tipos de combarbalitas identificadas en la zona, la balsa y las otras esculturas labradas sobre la roca talcosa de color rojo, deberían corresponder al tipo 3 (Rosales et al. 1993), por su color rojizo-violáceo y textura brechosa. Los resultados obtenidos del análisis petrográfico realizado sobre la balsa en 1953 concuerdan con la combarbalita tipo 3, aunque en esos años no fue atribuido a este tipo particular de roca, simplemente porque no contaban con muestras locales de referencia para poder compararlas. Quedó por esto como andesita, la roca conocida para la región.

Tienen en común estas esculturas la temática marina; son peces y una balsa. No obstante, todo parece indicar que su lugar de producción fue lejos del mar, en el área de Cogotí y Combarbalá, distantes a más de 55 kilómetros del litoral. De ser así, es indudable que alguna ligazón existió entre los valles interiores y la costa del Pacífico en la era de estas esculturas, y más aún, que quienes las labraron conocían muy bien los rasgos físicos, morfológicos, etológicos y tecnológicos tanto de la balsa de cuero de lobo marino como de al menos tres especies de peces. Un cuerpo de conocimientos sobre el mar, junto a los seres y cosas que lo conforman, que circuló muy lejos de la orilla y hacia el interior del semiárido. Interesante es que, hasta el momento, ninguno de estos objetos de temas marinos ha sido encontrado asociado a sujetos o colectivos directamente ligados al mar. ¡Quién sabe!, la respuesta puede ser una lógica de oposiciones y dicotomías.

Otra arista queda aún por tocar en el campo de los correlatos de piedra. Gualterio Looser (1983) menciona una pieza emparentada a las series anteriores, encontrada por Francisco San Román al abrirse los cimientos de una casa en la ciudad de Copiapó (Barros 1895). La escultura figura a un personaje antropomorfo que con sus dos manos carga sobre su cabeza un receptáculo cilíndrico, todo labrado sobre un mismo bloque de piedra que parece ser la misma combarbalita roja-violácea, talcosa y brechosa de las piezas anteriores (fig. $8 \mathrm{~h}$ ). El sujeto fue representado sentado y con los pies hacia adelante, con los codos hacia el frente y sobre una pequeña plataforma. No existen detalles de los dedos de sus pies o de sus manos. Los rasgos faciales recuerdan inmediatamente a los tripulantes de la balsa, en especial por la forma de la cara y la manera de modelar en bajorrelieve la nariz y las cavidades oculares; sutilezas que podrían respon- der a un mismo estilo representacional. Una escultura similar, aunque de rasgos antropomorfos menos claros, fue hallada en las cercanías de Illapel (Ampuero 1978), la cual según Walter Ruben (1952) -quien fotografió ambas esculturas- sería parte de la Colección Irarrázabal ubicada en Santiago. Junto a ellos, existen otros contenedores de piedra recuperados en la Región de Coquimbo semejantes a estos objetos, en especial por su calidad de recipiente y el tipo de roca empleada, aunque sin modelados figurativos, con receptáculos de distintas formas y con mangos planos laterales (Cornely 1947-1949, Iribarren 1973 ).

Si las fuentes de este tipo de roca son focalizadas y circunscritas, la producción de estos objetos debió estar anclada en ellas. La existencia de ejemplares terminados en los potreros inmediatos a la veta demuestra que fueron labrados en el mismo lugar, mientras que el hallazgo de objetos análogos en sitios lejanos implica que las piezas viajaron necesariamente de la mano de personas y a raíz de ciertas condicionantes sociales -sean las que hayan sido-. Es el caso de la balsa aparecida en Altovalsol al interior de La Serena (125 km aprox.), el del personaje con el contenedor en la cabeza del valle de Copiapó (400 $\mathrm{km}$ aprox.) o el de los peces que supuestamente fueron encontrados en el Cusco (2000 km aprox.).

No hay razón para dudar de antemano que algunas de estas piezas pudieran realmente haber llegado hasta el Cusco, como sugiere Gualterio Looser (1983). No olvidemos que al menos dos viajaron tiempo después muchísimo más lejos, una hasta Ginebra en Suiza (11.500 km aprox.) y la otra hasta Hamburgo en Alemania (12.200 km aprox.). Más allá de la posibilidad de que los objetos se desplazaran o no largas distancias, lo que debiera intrigarnos y concentrar nuestra atención son las relaciones sociales y los sujetos que estuvieron detrás de dichos movimientos, pues yace en esas articulaciones, motivaciones y condiciones el potencial real de movilidad de los bienes, y no en las distancias absolutas entre los puntos. Ahora que conocemos la compleja ruta de la balsa hasta Hamburgo y la cantidad de manos por las que circuló a lo largo de su historia, por qué dudar tajantemente que, dentro del sistema comercial, tributario y de ofrendas del Imperio inca, una escultura haya sido transportada hasta el Cusco. No dejemos que nuestros prejuicios nos cieguen, recordemos que, lamentablemente, sabemos más acerca de los objetos que llegaron con el Inca que de aquellos que se fueron en sus manos y sobre sus recuas. 
Para cerrar, fuera del campo de la piedra labrada y ahora en el ámbito de la arcilla cocida, algunos correlatos iniciales pueden establecerse. La forma en que fueron representadas las cabezas de ambos tripulantes de la balsa de piedra se asemeja bastante a aquellas modeladas en algunos jarros patos Diaguita y Diaguita Inca, en especial en el rasgo aplanado de su sección superior y en las protuberancias circulares laterales (Ampuero 1978: 46, Carmona \& Varela 2017: figs. 3 y 4, Cornely 1947: figs. 4-7, Cornely 1947-1949: fig. 81). Algunas de estas singulares vasijas provienen también del área de Altovalsol, por lo que sus correlaciones pueden ser sumamente significativas al momento de situar la balsa en un marco geográfico, estilístico y temporal.

\section{LA BALSA DE LA ALIANZA}

En torno a la famosa Arca de la Alianza rondan desde hace siglos cientos de mitos e historias. La protagonizada por Harrison Ford es probablemente solo la adaptación hollywoodense de un sinfín de versiones creadas en diferentes rincones del planeta y repetidas en varias lenguas. Su color, su forma, quién la construyó, por manos de quiénes pasó, dónde está guardada y cuál es su función; todas variantes de una misma estructura. Un fenómeno similar -aunque a otra escala, claroocurre con la escultura de piedra que ha servido de eje a este ensayo.

A través de los relatos de la balsa se encadenaron historias que con el tiempo se convirtieron en realidades, debido en parte al desinterés por volver a las fuentes y de juzgar los discursos previos. El objeto original sirvió de insumo para crear múltiples objetos virtuales de diversa naturaleza, tiempo y audiencia. Un fenómeno mutacional que debe ser sin lugar a dudas más potente en objetos emblemáticos de la prehistoria, tal como la balsa de piedra, pero cabe preguntarse si las biografías y realidades de todos los objetos no viven también estos procesos de metamorfosis al pasar de boca en boca, la excesiva confianza y el arrumado citatorio de referencias sobre referencias. Es por esto que, querámoslo o no, una cuota de ficción yace siempre bajo el discurso arqueológico.

La escultura es roja y no gris, está elaborada de combarbalita tipo 3 y no de andesita, no fue encontrada en un cementerio Diaguita Inca propiamente tal, sino aislada en un potrero de arado que probablemente había destruido cementerios preexistentes; esto si aceptamos su proveniencia, para lo cual debemos confiar a ojos cerrados en la palabra de una niña de 14 años que apareció en el consultorio de un famoso coleccionista para venderle un objeto de semblanza antigua, un fantasma de la historia de quien nunca más supimos. Tal vez debemos dejar de lado el afán por entregar respuestas rápidas que silencien los debates, y darnos cuenta de que una de las mayores riquezas de la investigación yace más bien en crear interrogantes $\mathrm{y}$ abrir preguntas.

Casualmente, el mismo año en que fue ambientada la película de Spielberg y que comenzaron las negociaciones por la compra de la colección arqueológica Schwenn, Walter Benjamin escribía su famoso ensayo La obra de arte en la época de su reproductibilidad técnica (2013). De forma brillante y lúcida, el escritor alemán defiende la tesis de que aun a la reproducción más perfecta de una obra de arte le faltará siempre una cosa, el aquí y el ahora, el carácter absolutamente único de su existencia y del lugar mismo donde se encuentra. Es justamente este "aquí-y-ahora" del original el que define su autenticidad, cualidad interna que ninguna de sus réplicas podrá jamás tener, precisamente, porque no es posible reproducir la autenticidad.

La balsa de piedra fue difundida masivamente en distintos países y continentes sin moverse de su vitrina. Siguiendo a Walter Benjamin, aumentó cualitativamente su potencial de exposición. Una primera y única fotografía se duplicó, republicó y multiplicó por más de cincuenta años en diversos artículos y libros. Desde esta primigenia fotografía -ya no desde el objeto original de piedra- se reprodujeron dibujos y modelaron réplicas en volumen para exponerlas en catálogos y en exhibiciones permanentes de museos. Sin salir de su escaparate en Hamburgo, la balsa hizo todo el viaje de retorno hasta sus orígenes gracias a distintas técnicas de reproducción del objeto: escritura, dibujo, fotografía y escultura. Sus biografías son derroteros paralelos de viajes físicos y virtuales que la llevaron de la singularidad a la multiplicación, de un cuerpo auténtico a cientos de soportes. Lo más interesante, y que complejiza aún más el encadenamiento, es que la pieza original ya es en sí una representación de otro objeto previo, la balsa de cuero de lobo marino, un tipo de embarcación usada por más de mil años en las costas de Atacama ${ }^{14} \sin$ grandes transformaciones en su diseño, materiales de construcción y tecnología. 
Aun así, la obra es sorprendentemente única. $\mathrm{Al}$ revisar la literatura de la zona no asoma ningún objeto similar en el universo de la cultura material precolombina, salvo tal vez las esculturas de peces y el personaje con el contenedor sobre su cabeza, emparentados por el tema marino o el tipo de roca. Situación que asombra aún más si lo comparamos con la alfarería de la región, pues se produjeron cientos y tal vez miles de vasijas decoradas de alto valor estético y calidad artefactual siguiendo estrechos cánones estilísticos en la misma época. Frente a esta evidente ostentación de obras de arte en arcilla cocida, la escultura de la balsa de piedra es excepcional y extraña. La cerámica Diaguita es así lo opuesto a la escultura de la época. No obstante, la pulcritud y perfección del modelado de la balsa demuestran gran destreza técnica, profundos saberes sobre la materia y un diseño preconcebido. Se seleccionó el bloque conociendo el volumen final de la obra, las unidades constitutivas fueron escogidas y dispuestas siguiendo una lógica composicional; nada quedó al azar. Resulta paradójico entonces pensar que una obra de estas características sea única. ¿Dónde queda el ensayo, la práctica, los intentos fallidos, el progreso técnico, el aprendizaje y las reproducciones?, ¿dónde se replica el conocimiento, el estilo y el saber hacer?, ¿será que no existieron objetos análogos o es solo que el registro arqueológico, por su naturaleza e historia, no nos permite verlo?

\section{BIOGRAFÍAS: TRAYECTORIAS E INSCRIPCIONES}

¿Por cuántas manos pasó la balsa de piedra desde su escultor hasta hoy, cientos de años después? Revisamos solo algunos casos a partir de la información disponible, y aun así, el listado es abultado. Desde la niña del consultorio médico entre 1936 y 1939, Ricardo Schwenn, el fotógrafo Walter Kahler, seguido por el farmacéutico R. Kämer y por Max Uhle en 1939, por el técnico que hizo el corte petrográfico en 1953, el ladrón o la ladrona y la policía alemana en 1962, los sucesivos curadores de la sección de América del museo durante décadas, hasta que llegó a mis manos en febrero de 2019. Seguirá, sin dudas, pasando de mano en mano, y ni hablar de cuántas personas la mirarán en la vitrina de la exhibición “Tesoros Andinos". Todas ellas y todos ellos -incluyéndome- establecieron en cierta medida un lazo con el resto, un vínculo mediado por este objeto material, por un trozo de roca esculpido cientos de años atrás, que más allá de su vida junto a sus creadores, sigue hasta hoy articulando redes sociales, sosteniendo realidades, expresando sentidos y portando valor. Una cualidad increíble de la cultura material que no es exclusiva de esta pieza, sino por el contrario, más habitual y cotidiana de lo que imaginamos. En este ensayo la balsa sirvió solo de excusa para develar a través de un ejemplo las tramas y urdimbres que las cosas coligan a su alrededor.

Los objetos no poseen solo tres dimensiones, sino tantas como busquemos. Se puede abusar de ellos desmenuzándolos una y otra vez, arista por arista, recoveco a recoveco, para interpelar todas y cada una de las perspectivas posibles. Su materia logra volverse tan densa y espesa como queramos. Así, aquella roca que parece sólida e inmutable consigue fragmentarse, expandirse y multiplicarse a niveles insospechados si se sabe interrogar. Un único y singular objeto se convierte de esta manera en la excusa perfecta para reflexionar acerca de todo lo que ocurre y ha ocurrido en torno a él, la conjugación de acontecimientos, sujetos, relaciones, visiones, imaginarios, épocas, lugares y otros objetos. No debemos olvidar, sin embargo, que el devenir de la balsa de piedra no acaba aún de escribirse, y que este ensayo será, con el paso del tiempo, otra simple biografía que inscribe parte de su historia sobre un manojo de papeles. Se trata únicamente de un gesto de archivo en el sentido de Jacques Derrida (1995, 2014). Una pulsión de destrucción ante un olvido inminente -olvido del original por la irrupción de los sustitutos virtuales- en el cual se intenta trazar, marcar y registrar; deconstruir y crear. Un archivo repleto de fotografías y retratos escritos acerca de una obra distante y brumosa que por alguna razón todos buscan y quieren ver, tal como al Arca de la Alianza.

AgradeCimientos ANid/CONICYT-FONDECYT 1190263. Este ensayo fue posible únicamente gracias a la amabilidad y disposición de Christine Chávez, curadora del área de América del Museum am Rothenbaum. Gloria Cabello fue la responsable de que desviara la mirada de la balsa, invitándome a descubrir otras esculturas de piedra de la región. Discutimos sobre combarbalitas, contenedores, tabletas, morteros, recipientes, peces y rostros humanos; su apoyo fue fundamental. José Berenguer ayudó a rastrear la biografía de las fotografías y réplicas de la pieza. Daniel Hernández cargó con la ardua tarea de leer y procesar los documentos en alemán. Gracias a Javier Gómez tuve acceso a las réplicas de la escultura depositadas en el Museo Arqueológico de La Serena. José Blanco aclaró todas mis dudas sobre rocas y petrografía. Gabriel Cantarutti compartió con nosotros la información sobre la Crocker 
Collection del American Museum of Natural History de Nueva York. Boris Santander y Marcelo González ayudaron a conseguir un texto clave de la literatura chilena sobre el tema. Marcela Sepúlveda, como siempre, escuchó con paciencia cada anécdota y detalle de la singular historia. Agradezco además al Museum am Rothenbaum (Alemania), Museo Nacional de Historia Natural (Chile), al Museo Arqueológico de La Serena (Chile) y al Museo Etnográfico de Ginebra (Suiza) por facilitar las fotografías de los objetos que guardan en sus colecciones. Finalmente, mi más sincera gratitud a los/as evaluadores/as del manuscrito y a Paula Martínez por su excelente trabajo editorial.

\section{NOTAS}

${ }^{1}$ El título original de la película es Raiders of the Lost Ark.

${ }^{2}$ En español, Museo en el Rothenbaum, Culturas y Artes del Mundo.

${ }^{3}$ En español, Museo Etnográfico de Hamburgo. Este fue su nombre hasta el verano de 2018 en que ambia a Museum am Rothenbaum - Kulturen und Künste der Welt (MARKK).

${ }^{4}$ Archivo Documental de la Colección Schween.

${ }^{5}$ No olvidemos que Francisco Cornely nació en Ehrenbreitstein en 1882, que allá estudió en su juventud y que escribió varios artículos en esta lengua (Montané 1973).

${ }^{6}$ Un manuscrito de Jorge Iribarren fechado en 1976 advierte de excavaciones de túmulos funerarios por parte de $\mathrm{Ri}$ cardo Schwenn en el área de Cachiyuyo, mismo lugar señalado por Ricardo Latcham (Castillo \& Kuzmanic 1981: 151).

${ }^{7}$ Los tres recortes de periódicos son parte del archivo documental de la colección Schwenn del Museum am Rothenbaum.

${ }^{8}$ El resto de los objetos en exhibición poseen diversas procedencias como Quillagua, Lasana, Caldera, Taltal y La Serena. No todos son de la colección comprada a Ricardo Schwenn, ya que al menos otras tres colecciones del museo provienen del norte de Chile: la del señor Eggers, donada en 1927 cuyo origen es Lasana; la de Oskar Schmidt-Pizarro, de Taltal que dice "chango (Chile)" y la del señor Gutzschebauch, de Quillagua que data del año 1900.

${ }^{9}$ La cavidad central posee $11,35 \mathrm{~cm}$ de largo, $9,02 \mathrm{~cm}$ en su sección más ancha y $3 \mathrm{~cm}$ de profundidad.

${ }^{10}$ Alcanzan los tres centímetros de alto desde la cubierta de la balsa hasta la parte alta de la cabeza.

${ }^{11}$ Las figuras son más anchas de hombro que altas respecto de la cubierta de la balsa.

${ }^{12}$ Miden entre 5,5 y $5 \mathrm{~cm}$ de largo por $2 \mathrm{~cm}$ de ancho.

${ }^{13}$ En el catálogo se detallan 138 lotes chilenos para la venta, cada uno compuesto de un número variable de piezas, desde dos vasijas cerámicas hasta más de 160 objetos. Se describen obras de Taltal, Caldera, Copiapó, Coquimbo, Arica, Antofagasta, Lebu, Ancud, Calama, Pichilemu, "Diaguita" y "Araucanos", entre otros. El resto de la colección la componen piezas de Perú, Bolivia, Costa Rica, Colombia, México y Ecuador. Una parte de esta colección está hoy depositada en el British Museum, adquirida en 1939, mismo año en que la Sotheby \& Co. realiza la subasta en Londres (British Museum 1939).

${ }^{14}$ Las dataciones radiocarbónicas más antiguas de restos de balsas de cuero de lobo son de aproximadamente el 800 cal DC (Ballester et al. 2014, 2015; Bittmann 1978; Núñez 1986), y se mantuvo en uso en algunos lugares de la costa del desierto de Atacama hasta las primeras décadas del siglo xx (Álvarez 1999; Capdeville 1921; Iribarren 1955; Latcham 1910, 1915, 1928; Mettler 1933; Niemeyer 1965-1966).

\section{REFERENCIAS}

Alberti, S. 2005. Objects and the museum. Isis 96 (4): 559-571.

Álvarez, L. 1999. Balsas de totora, de madera y de cueros de lobos en la prehistoria de Arica. Diálogo Andino 18: 21-38.

Ampuero, G. 1978. Cultura Diaguita. La Serena: Ministerio de Educación, Departamento de Extensión Cultural.

Ampuero, G. 1986. Diaguitas. Pueblos del norte verde. Santiago: Museo Chileno de Arte Precolombino.

ANónimo. 1919. Memoria, plan de estudios i reglamento del Instituto Superior de Educación Física correspondiente al año 1918. Santiago: Imprenta Universitaria.

Anónimo. 1921. Boletín de Instrucción Pública. Anales de la Universidad de Chile 168 (79): 3-275.

Anónimo. 1925. Índice de títulos conferidos por la Universidad de Chile en 1925. Anales de la Universidad de Chile 3 (2): 917-962.

Ballester, B. \& San Francisco, A. 2017. Cuerpo del convite. Santiago: Ojo en Tinta.

Ballester, B., Clarot, A. \& Llagostera, A. 2014. El Cementerio de Auto Club de Antofagasta y la sociedad litoral entre los 1000 y 1450 DC. Hombre y Desierto 18: 187-212.

Ballester, B., Gallardo, F. \& Aguilera, P. 2015. Representaciones que navegan más allá de sus aguas: una pintura estilo El Médano a más de $250 \mathrm{~km}$ de su sitio homónimo. Boletín de la Sociedad Chilena de Arqueología 45: 81-94.

Barros, D. 1895. El dios Viracocha. Actes de la Société Scientifique du Chili 5: 198-201.

BECHER, H. 1953. Ein archäologischer Beleg für das vorkolumbische Auftreten der Robbenhaut-Balsa an der Nordküste Chiles. Zeitschrift für Ethnologie 78 (2): 257-261.

Benjamin, W. 2013. L'oeuvre d'art à l'époque de sa reproductibilité technique. Paris: Éditions Payot \& Rivages.

Berenguer, J. 2008. Naves prehispánicas en el mar de los changos. In Pescadores de la niebla. Los changos y sus ancestros, L. Cornejo, Ed., pp. 31-39. Santiago: Museo Chileno de Arte Precolombino.

Berenguer, J. \& Torres, A. 2011. Compartiendo memorias: 30 años del Museo Chileno de Arte Precolombino. Santiago: Museo Chileno de Arte Precolombino. 
Bittmann, B. 1978. Fishermen, mummies and balsa rafts on the coast of northern Chile. El Dorado 3 (3): 60-103.

Bresson, A. 1875. Le désert d'Atacama et Caracoles. Le tour du Monde 29: 321-352.

British Museum. 1939. The British Museum Quarterly 13 (2): 60-68.

Cabello, G. 2016. Breve historia diaguita antes del arribo de los conquistadores españoles. In El arte de ser Diaguita, Museo Chileno de Arte Precolombino, Ed., pp. 17-45. Santiago: Museo Chileno de Arte Precolombino.

Capdeville, A. 1921. Ms. Arqueología. Notas de campo de Septiembre de 1921. Cuaderno inédito parte del Archivo del Museo Augusto Capdeville Rojas de Taltal.

Carmona, G. \& VArela, G. 2017. Estudio exploratorio de los textiles diaguita y diaguita-inka a través de la iconografía de su cerámica. Informes FAIP 2017: 123-144.

Castillo, G. \& Kuzmanic, I. 1979-1981. Registro de colecciones inéditas del Complejo Cultural El Molle. Boletín del Museo Arqueológico de La Serena 17: 122-231.

Cornejo, L. 1989. El plato zoomorfo Diaguita: variabilidad y especificidad. Boletín del Museo Chileno de Arte Precolombino 3: 47-80.

Cornely, F. 1947. Influencia incaica en la cerámica diaguita chilena. Boletín del Museo Arqueológico de La Serena 3: 10-19.

Cornely, F. 1947-1949. Cultura diaguita-chilena. Revista Chilena de Historia Natural 51/53: 119-262.

Cornely, F. 1949. Algunas cerámicas con influencia incaica encontradas en el Valle de Elqui. Boletín del Museo Arqueológico de La Serena 4: 2-11.

Cornely, F. 1955. Decoración artística de la alfarería de los indios de Coquimbo y Atacama. Notas del Museo Arqueológico de La Serena 3: 1-4.

Cornely, F. 1956. La alfarería de uso doméstico de los diaguitas chilenos. Boletín del Museo Arqueológico de La Serena 8: 1-6.

Derrida, J. 1995. Archive fever: a freudian impression. Diacritics 25 (2): 9-63.

DerridA, J. 2014. Trace et archive, image et art. Paris: INA Éditions.

Duplessis. 2003. Périple de Beauchesne á la Terre de Feu (1698-1701). Une expédition mandatée par Louis XIV. Paris: Transboréal.

FeUILLÉE, L. 1714. Journal des observations physiques, mathematiques et botaniques, faites par l'ordre du Roy sur les côtes orientales de l'Amérique meridionale, et dans les Indes Occidentales, depuis l'année 1707 jusque en 1712. Paris: Pierre Giffart.

Frezier, M. 1717. Relation du voyage de la mer du sud aux côtes du Chili, du Perou, et du Bresil, fait pendant les années 1712, 1713 \& 1714. Amsterdam: Pierre Humbert.

GaY, C. 1854. Atlas de la historia física y política de Chile. Tomo 1. Paris: Imprenta de E. Thunot y Ca.

Gómez, J. 2009. Restauración de cerámicas patrimoniales del Museo Arqueológico de La Serena. Tesis de especialización de Postítulo de Restauración del Patrimonio Cultural
Mueble, Facultad de Artes, Escuela de Artes, Universidad de Chile. Santiago.

GonzÁlez, P. 1998a. Códigos visuales de los diseños diaguita pre incaicos: felinos, simetría e identidad. In Actas del III Congreso Chileno de Antropología, Tomo 1, pp. 395-402. Temuco: Colegio de Antropólogos de Chile A.G.

GonzÁLEZ, P. 1998b. Doble reflexión especular en los diseños diaguita-inca: de la imagen al símbolo. Boletín del Museo Chileno de Arte Precolombino 7: 39-52.

GonZÁlez, P. 2001. Estructura del arte, espacio e identidad: la cultura Diaguita en el valle de Illapel. In Actas del IV Congreso Chileno de Antropología, Tomo 2, pp. 1377-1382. Santiago: Colegio de Antropólogos de Chile A.G.

GonzÁLEZ, P. 2004. Arte visual, espacio y poder: manejo incaico de la iconografía cerámica en distintos asentamientos de la fase Diaguita Inka en el valle de Illapel. Chungara 36 (2): 375-392.

GonZÁLEZ, P. 2006. Diaguitas a través de las imágenes: chamanismo y dualidad en el norte semiárido chileno. Revista de Arqueología Americana 24: 143-171.

Gosden, C. \& MARShall, Y. 1999. The cultural biography of objects. World Archaeology 31 (2): 169-178.

HABERLAND, W. 1984. Bootförmige schale. In Hamburgisches Museum für Völkerkunde, Führer durch die Sammlungen, J. Zwernemann, Ed., p. 335. Munich: Prestel.

Hoskins, J. 2006. Agency, biography and objects. In Handbook of material culture, C. W. Tilley, S. Keane, M. Kuechler, M. Rowlands \& P. Spyer, Eds., pp. 74-84. London: SAGE Publications.

IrIBARREN, J. 1955. Los últimos constructores de balsas de cueros de lobos. Notas del Museo Arqueológico de La Serena 1: 1-4.

Iribarren, J. 1957. La flauta de Pan y otros instrumentos indígenas. Boletín del Museo Arqueológico de La Serena 9: 12-21.

IrIbarRen, J. 1962. Minas de explotación por los Incas y otros yacimientos arqueológicos en la zona de Almirante Latorre, Departamento de La Serena. Boletín del Museo Arqueológico de La Serena 12: 61-72.

IrIBARREN, J. 1971. Instrumentos musicales del Norte Chico chileno (Provincias de Atacama y Coquimbo). Boletín del Museo Arqueológico de La Serena 14: 7-39.

IrIbARREN, J. 1973. La arqueología en el Departamento de Combarbalá (Provincia de Coquimbo, Chile). Boletín del Museo Arqueológico de La Serena 15: 7-113.

KорутоғF, I. 1991. La biografía cultural de las cosas: la mercantilización como proceso. In La vida social de las cosas. Perspectiva cultural de las mercancías, A. Appadurai, Ed., pp. 89-124. Mexico City: Grijalbo.

Latcham, R. 1910. Los changos de las costas de Chile. Santiago: Imprenta Cervantes.

LATCHAM, R. 1915. Uso y preparación de pieles entre los indios de Chile y otros países de Sud-América. Revista Chilena de Historia y Geografía 13 (17): 246-263. 
Latcham, R. 1928. La navegación entre los indios chilenos. La Información 117: 1006-1014.

Latcham, R. 1940. Observaciones acerca de la cultura "El Molle". Boletín del Museo Nacional de Historia Natural 18: 17-21.

Looser, G. 1926. Las tabletas para tomar rapé del Museo Nacional. Revista Chilena de Historia Natural 30: 19-22.

Looser, G. 1935. Objetos líticos ictiomorfos de la arqueología chilena. Revista Chilena de Historia Natural 39: 47-50.

Looser, G. 1938. Las balsas de cuero de lobos de la costa de Chile. Revista Chilena de Historia Natural 42: 232-266.

Looser, G. 1960. Las balsas de cueros de lobo inflados de la costa de Chile. Revista Universitaria 64/65: 247-273.

Looser, G. 1983. Esculturas de piedra de aspecto "chileno" halladas en el Cuzco. Noticiario Mensual del Museo Nacional de Historia Natural 310: 10-14.

LOTHRop, S. 1932. Aboriginal navigation off the west coast of South America. The Journal of the Royal Anthropological Institute of Great Britain and Ireland 62: 229-256.

Marcoy, P. 1875. Travels in South America, from the Pacific Ocean to the Atlantic Ocean. New York: Scribner Armstrong Co.

Mettler, A. 1933. Le cimetière "Chango" de Cruz Grande, Chili. Journal de la Société des Américanistes 25 (1): 99-101.

Miers, J. 1826. Travels in Chile and La Plata, including accounts respecting the geography, geology, statistics, government, finances, agriculture, manners and customs, and the mining operation in Chile. London: Printed for Baldwin, Cradock, and Joy.

Montané, J. 1973. Francisco Cornely Bachmann (1882-1969). Boletín Bibliográfico de Antropología Americana 36 (45): 201-204.

Niemeyer, H. 1965-1966. Una balsa de cueros de lobo de la caleta de Chañaral de Aceituno (Prov. de Atacama, Chile). Revista Universitaria 50/51 (28/29): 257-269.
NúÑEZ, L. 1986. Balsas prehistóricas del litoral chileno: grupos, funciones y secuencia. Boletín del Museo Chileno de Arte Precolombino 1: 11-35.

NúñEz, P. \& Contreras, R. 2009. A propósito de una miniatura de balsa en Taltal, contemporánea con Chinchorro. Taltalia 2: 98-110.

Pérez De ArCe, J. 2014. Flautas de piedra combarbalita morada de Chile Central y Norte Semiárido. Boletín del Museo Chileno de Arte Precolombino 19 (2): 29-54.

PhilipPI, R. 1860. Viage al desierto de Atacama hecho de orden del gobierno de Chile. Halle: Librería Eduardo Anton.

Rosales, G., Vergara, M., S. Helle, S., Kelm, S., Cucurella, J., Flores, I. \& Oyarzún, J. 1993. Mineralogía y génesis de la combarbalita en el norte de Chile. Revista Geológica de Chile 20 (2): 229-235.

Ruben, W. 1952. Tiahuanaco, Atacama und Araukaner. Drei vorinkaische Kulturen. Leipzig: Otto Harrassowitz.

Servicio Nacional De Salud. 1959. Guía Médica Nacional. Presiones médicas y paramédicas. Santiago.

SLuSSER, M. 1950. Preliminary archaeological studies of northern central Chile. PhD Thesis Dissertation in the Faculty of Political Science, Columbia University, Nueva York.

Sotheв \& Co. 1939. Catalogue of the Celebrated Carlos Cruz Montt Collection of South American Antiquities. London: Sotheby \& Co.

Troncoso, A. 2005. El plato zoomorfo/antropomorfo Diaguita: una hipótesis interpretativa. Werkén 6: 113-123.

WASHBurn, D. 2018. Cognitive archaeology: a symmetry/ symmetry-breaking model for the analysis of societies. Time \& Mind 11 (2): 121-161. 